\title{
Interactive Aerosol Feedbacks on Photolysis Rates in the GEM- MACH v2.4 Air Quality Model in Canadian Urban and Industrial Areas
}

Mahtab Majdzadeh, Craig A. Stroud, Christopher Sioris, Paul A. Makar, Ayodeji Akingunola, Chris McLinden, Xiaoyi Zhao, Michael D. Moran, Ihab Abboud, Jack Chen

Air Quality Research Division, Environment and Climate Change Canada, Toronto, ON, M3H5T, Canada

Correspondence to: Craig Stroud (craig.stroud@ec.gc.ca)

Abstract. The photolysis module in Environment and Climate Change Canada's on-line chemical transport model GEMMACH (GEM: Global Environmental Multi-scale - MACH: Modelling Air quality and Chemis try) was improved, to make use of the on-line size and composition-resolved representation of atmospheric aerosols and relative humidity in GEM-MACH, to account for aerosol attenuation of radiation in the photolysis calculation. We coupled both the GEM-MACH aerosol module and the MESSy-JVAL(Modular Earth Sub-Model System) photolysis module, through the use of theon-line aerosol modeled data and a new Mie lookup table for the model-generated extinction efficiency, absorption and scattering cross sections of each aerosol type. The new algorithmapplies a lensing correction factor to the black carbon absorption efficiency (core-shell parameterization) and calculates the scattering and absorption optical depth and as ymmetry factor of black carbon, sea-salt, dust, and other internally mixed components.

We carried out a series of simulations with the improved version of MESSy-JVAL and wildfire emis sion inputs from the Canadian Forest Fire Emis sions Prediction System (CFFEPS) for two months, compared the model aerosol optical depth (AOD) output to the previous version of MESSy-JVAL, s atellite data, ground-based meas urements and re-analysis products, and evaluated the effects of AOD calculations and the interactive aerosol feedback on the performance of the GEM-MACH model. The comparis on of the improved version of MESSy-JVAL with the previous version showed significant improvements in the model performance with the implementation of the new photolysis module, and with adopting the online interactive aerosol concentrations in GEM-MACH. Incorporating these changes to the model resulted in an increase in the correlation coefficient from 0.17 to 0.37 between the GEM-MACH model AOD one-month hourly output and AERONET (Aerosol Robotic Network) measurements across all the North American sites. Comparisons of the updated model AOD with AERONET measurements for selected Canadian urban and industrial sites s pecifically, showed better correlation coefficients for urban AERONET sites, and for stations located further south in the domain for both simulation periods (June and January 2018). The predicted monthly averaged AOD using the improved photolysis module followed the spatial patterns of MERRA2 re-analys is (Modern-Era Retrospective analysis for Research and Applications - Version 2), with an overall under-prediction of AOD over the common domain for both seasons. Our study als o suggests that the domain -wide impact of direct and indirect 
effect aeros ol feedbacks on the photoly sis rates from meteorological changes, are considerably greater ( 3 to 4 times) than the direct aerosol optical effect on the photoly sis rate calculations.

\section{Introduction}

Atmospheric aerosols are very small solid, aqueous or mixed-state particles suspended in the atmosphere, typically ranging from $10^{-3} \mu \mathrm{m}$ to $10 \mu \mathrm{m}$ in size, which affect Earth's radiative balance (Bond and Bergstrom, 2006). Photolysis or photodis sociation reactions are those for which molecules break down by absorbing sunlight. Aerosol particles scatter and absorb solar radiation, and can thus change the actinic fluxes, or the flux of spherically integrated spectral radiance of the sun, and hence the rate coefficients of photolysis reactions, also known as J-values (Jacobson, 2005). The latter are the rates of the molecular dis sociation of the gaseous s pecies by sunlight and depend on the attenuation of the radiation stream as a function of the particle size, composition and morphology (arrangement of the components within the particle), on gases' effective size (molecular cross-section), and on the fraction of molecules broken apart per incoming photon (quantum yield). One way of quantifying the effects of aerosols on radiative transfer processes, including photoly sis, is through the use of the aerosol optical depth (hereafter AOD). AOD is a dimensionless quantity, a measure of the extinction of the solar light by aerosols in the atmosphere and provides a measure of the amount of aerosols in a vertical column fromthe surface to the top of the atmosphere. Aerosol mixing state within a population of aerosol particles is defined as the dis tribution of chemical species in each aerosol particle (Riemer et al., 2019), and can also be referred to as the particle morphology in the aerosol population (Stevens and Dastoor, 2019). When all the species are homogeneously mixed within an aerosol particle, the population is known to be "internally mixed", whereas an "externally mixed" population of particles consists of only one chemical species. Intemal mixtures can also be described as homogeneous populations of homogeneous particles, and external mixtures as heterogeneous populations of homogeneous particles (Bond and Bergstrom, 2006). In reality, completely internally and externally mixed aeros ol populations are rare in the atmo sphere, and aerosol particles are complexmixtures of different chemical species (Bond et al., 2006; Riemer et al., 2019; Healy et al., 2014).

Black Carbon (a widely used termfor light-absorbing carbon) fromfos sil fuel and biomass burning is known to have a large positive radiative forcing in the atmosphere due to its highly absorptive properties and strong extinction (Jacobson, 2000; Bond and Bergstrom, 2006). Black carbon can exist in different mixing states: externally mixed, where black carbon and other aerosols are in separate particles, volume-averaged internally mixed, where each particle contains a mixture of black carbon and other aerosols, and a core-shell structure, in which each particle consists of a black carbon core surrounded by a mixture of other aerosols through condensation and coagulation or aging processes (Jacobson, 2001). When black carbon is coated with other aerosols, the light absorbing properties of black carbon may be enhanced (absorption enhancement) by 50 to $60 \%$ through a lensing effect (Liu et al., 2017). Since absorption, and therefore the radiative forcing in the atmosphere, is influenced by different assumptions of the mixing state of particles, the representation of aerosol size and the mixing state of black carbon is essential to have a realistic estimation of radiative forcing in atmospheric models (Bond et al., 2006). Bond et al. (2006), 
calculated the absorption amplification (ratio of absorption by core-shell black carbon to pure black carbon with the same carbon mass) for a wide range of core-shell thickness, using an implementation of the Bohren and Huffman (1983) Mie scattering algorithmin MatLab (Mätzler, 2002) at $550 \mathrm{~nm}$. They identified five distinct geometric regimes for different black carbon (core) and shell sizes, and calculated the best fit for the absorption amplification for each individual regime (Bond et al. (2006), Table 2).

To date, the estimates of AOD in atmospheric models have been based on one or a combination of different mixing states of aerosols. The variation in the resulting aerosol optical properties from the atmospheric models is associated with the as sumptions regarding the methods used in AOD calculations, aerosol mixing states, density, refractive indexand hygroscopic growth, with the mostimportant factor being the choice of the mixing states of aerosols (Curci et al., 2015). The latter accounts for 30 to 35\% of the uncertainty in estimation of AOD and single scattering albedo (Curci et al., 2015). Other studies, e.g., Barnaba et al. (2010), found different spatial patterns in AOD versus surface particulate matter, highlighting the sensitivity of calculated AOD to aerosol vertical profile rather than the aerosol surface concentrations.

The radiative transfer module in chemical transport models contains parameterizations for extinction efficiency (the sum of scattering and absorption efficiencies), single scattering albedo (the ratio of scattering efficiency to total extinction efficiency) and as ymmetry factor (the angular direction of the scattered radiation by particles or gases) for each particle type, and calculates scattering and absorption coefficients (a measure of photon scattering and absorption by particles) to predict the radiative state of the atmosphere. AOD is calculated by integrating the extinction of the solar beam due to aerosols over the vertical column. These optical effects of aerosols may also influence the shorter wavelengths as sociated with atmospheric gas photolysis, influencing atmospheric reactivity. These processes may be harmonized in an on-line chemical transport model, such as Environment and Climate Change Canada's (ECCC) online-coupled meteorology and chemical transport model, GEM-MACH (GEM: Global Environmental Multi-scale - MACH: Modelling Air quality and Chemistry). Chemical trans port models such as GEM-MACH have been used in past works, investigating AOD and evaluating different aerosol light attenuation methods and mixing states of black carbon.

Gan et al. (2015) performed a long-term simulation of aerosol concentration and optical depth for 16 years (1995 to 2010), using the coupled Weather Research andForecasting-Community Multi-scale Air Quality (WRFv3.4 and CMAQv5.0.2) over the continental US (CONUS). For model evaluation, they used 16years (1995 to 2010) of observation data, and 14 years of AOD data (1997 to 2010) from several measurement networks including SURFRAD (Surface Radiation Budget Network), ARM (Atmospheric Radiation Measurement), CASTNET (Clean Air Status and Trend Network), and IMPROVE(Interagency Monitoring of Protection Visual Environments) observations (Gan et al., 2014a; Gan et al., 2015). The aerosol light attenuation method in their model was based on Mie and core-shell scattering (Gan et al., 2014b), and the model used online aerosol feedback on radiation and photolysis (sulfate, nitrate, ammonium, dust and organic aerosols) (Gan et al., 2015). Although their simulations showed the overall observed trends of AOD from SURFRAD, the magnitude of simulated AOD was underestimated compared to the observations. For instance, the 1997-2010 annual mean AOD time series over eastem US 
showed the model AOD values ranging from a minimu m of $\sim 0.06$ to a maximum of $\sim 0.09$, while SURFRAD observations had a minimum of $\sim 0.125$ and maximum of $\sim 0.175$.

Latimar et al. (2019) performed a 10-year simulation of aeros ol mas s scattering efficiency and AOD using the GEOS-Chem (Goddard Earth Observing System of the NASA Global Modeling and Assimilation Office, version 11-02, http://geoschem.org) chemical transport model. Their simulations of aerosol mass scattering efficiency, from an aerosol speciation including sulfate, ammonium, nitrate, primary and secondary organic carbon, mineral dust and sea-salt, were evaluated using data from the North American IMPROVE (Interagency Monitoring of Protected Visual Environments) monitoring network between 2000 to 2010; the global AERONET network data was used for AOD evaluation. Aerosol optical properties were generated using a GEOS-Chem default optical lookup table. They examined the impact of secondary inorganic aerosol and org anic aerosol size and hygroscopicity, excluding sites dominated by dust, and those with a high degree of internal sub-grid scale elevation variability, in order to focus on the composition/size is sues. The revised hygroscopicity as sumptions resulted in an increase of $19 \%$ in global mean simulated AOD with the revised aerosol optical properties. Despite improvements to simulated AOD on a global scale, those values were still underestimated at most North American sites (Latimar et al.,2019), with a correlation relation (R) of 0.78 and root mean square error (RMSE) of 0.1 for measured versus (revised) simulated AOD at all AERONET sites in 2006.

Alvarado et al. (2016) used measurements of aerosol scattering and absorption gathered during the 2008 Arctic Research of the Composition of the Troposphere from Aircraft and Satellites (ARCTAS) campaign to ev aluate the aerosoloptical properties from global numerical models. The NASA ARCTAS campaign (Jacob et al., 2010) was conducted over Alaska in April 2008 (ARCTAS-A) and over western Canada during June-July 2008 (ARCTAS-B). ARCTAS-CARB ("sponsored by the Califomia Air Resources Board (CARB)"), was conducted over California, one week prior to ARCTAS-B. Theseevaluations examined the effects of different mixing states of black carbon (volume-averaged, core-shell, and externally mixed, as well as the Maxwell-Garnet mixing rule, in which black carbon is assumed to be present in randomly dis tributed inclusions) on aerosol scattering and absorption properties, for wavelengths between 250 and $700 \mathrm{~nm}$, using an off-line approach of the Aerosol Simulation Program(ASP v2.1, Alvarado et al., 2015). ASP is a single-boxaerosol model, with modules to calculate aerosol thermodynamics, gas-to-aerosol mass transfer (condensation/evaporation), coagulation of aerosols, and aerosol optical properties (Alvarado et al., 2016). Using the instruments of the NASA Langley Aerosol Res earch Group (LARGE; Anderson et al., 1998), they showed that the use of a core-shell mixing state for black carbon, es pecially for fresh biomas s buming episodes, led to the overestimation of aerosol absorption by $29 \%$ to $35 \%$, with insignificant dependence on the wavelength, while an external mixture assumption led to the underestimation of aerosol absorption, with a strong dependence on wavelength. Their collected observations suggested using an externally mixed black carbon for the fresh s moke observations, and an internally mixed core-shell approach for the aged Arctic haze and the anthropogenic pollution. Their implementation of a variable mixing state resulted in an average overestimation of aerosol absorption of $10 \%$ at $470 \mathrm{~nm}, 17 \%$ at $532 \mathrm{~nm}$ and $23 \%$ at $660 \mathrm{~nm}$. 
https://doi.org/10.5194/gmd-2021-172

Preprint. Discussion started: 8 July 2021

(c) Author(s) 2021. CC BY 4.0 License.

(c) (i)

The mixing state of aerosols has a key impact on radiative transfer, with black carbon's ability to absorb significant amounts of incoming short wavelength light and re-emit this energy as longer wavelengths, resulting in its identification as a short-term climate forcer (IPCC, 2018). However, the mixing state of black carbon, and the impact of that mixing state on the radiative properties of atmos pheric aerosols, varies in the literature. Tombette et al. (2008) suggested that the mixing state of black carbon presents an insignificant effect on aerosol optical thickness (AOT) calculations (RMSE difference $<10^{-4}$ ). Liu et al. (2017) recommended using an absorption enhancement in order to account for optical lensing associated with biomass-buming emissions, and no-absorption enhancement for fresh traffic sources. In another study, over 10European AERONET (Aerosol Robotic Network) sites, Péré et al. (2009) found the mean modelled core-shell single scattering albedo (SSA) provided the closest match to the corresponding meas urements, with the spatio-temporal correlation coefficient of 0.51 (compared to 0.04 and 0.35 for the internally homogeneous and externally mixed particles respectively), and therefore is the best representation for simulating anthropogenic and/or biomass burning emissions.

140 In the work which follows, we make use of the Global Environmental Multiscale - Modelling Air-quality and Chemistry (GEM-MACH) model. The atmospheric chemistry module in GEM-MACH has been included as an on-line component of the core weather-forecast model(GEM) (Côté et al., 1998a, b; Girard et al., 2014; Charron et al., 2012), and consists of airquality processes, including computationally-efficient ADOM-II (Acid Deposition and Oxidant Model, version 2) gas-phase chemistry mechanism with 47 s pecies (Lurmann et al., 1986; Fung et al., 1991), aqueous phase and heterogeneous chemistry, wet and dry deposition, aerosol-cloud processes, and aerosol microphysics (Gong et al., 2003a, b; Moran et al., 2010; Makar et al., 2015a, b). The model's aerosol distribution is based on 12 particle size bins. The aerosol species in GEM-MACH consist of eight components within each size bin: ammonium, sulfate, nitrate, sea salt, crustal material, black carbon, primary organic aerosol (POA) and secondary organic aerosol (SOA). The aerosol and microphysical parameterizations include particle nucleation, condensation and coagulation (Gong et al., 2003a, b), gas and particle dry deposition (Zhang et al., 2001; Makar et al., 2018), cloud processing and in-cloud aqueous-phase chemistry (Gong et al., 2006), direct and indirect feedback options (Makar et al., 2015a, b; Gong et al., 2015) and equilibrium inorganic gas-aerosol partitioning (Makar et al., 2003). The model can be used with either one-way coupling (meteorology drives the chemistry) or with two-way coupling (which enables the model-generated aerosols' impact on radiative transfer - aerosol direct effect, and on radiative transfer via cloud formation aerosol indirect effect; Makar et al., 2015 a,b). However, the default configuration of GEM-MACH's photolysis calculations makes use of an a priori lookup table as a function of solar zenith angle and height. Here, we update this module, examine the effects of photolysis on the aerosol feedbacks, and show their relative importance to model performance.

Table 1 represents the different options for aerosoloptical calculations in the current version of GEM-MACH. The original, pre-calculated, clear-sky J-value lookup table in GEM-MACH is a function of solar zenith angle and height. The photolysis rates are calculated using the in put data of Peterson (1976) and the radiative transfer model of Dave (1972), with cros s-sections and quantum yields taken fromDeMore et al. (1988) (Kelly et al., 2012). The model uses theonline cloud fraction and liquid water content from the GEM model to scale the pre-calculated clear-sky J-values, based on an algorithmby Chang et al. (1987). The size distribution and number density profile of aerosols used in the lookup table generation were based on Bras lau and 
Dave (1973), and the refractive indexof the aerosols were assumed to be independent of height and waveleng th, with a single uniform value of 1.5-0.01i (Yamamoto and Tanaka, 1972). The resultant optical depth at 500 nm wavelength is 0.25.

\begin{tabular}{|c|c|c|c|c|c|c|}
\hline & Aerosol Size & $\begin{array}{l}\text { Aerosol } \\
\text { Chemistry }\end{array}$ & $\begin{array}{l}\text { Ozone } \\
\text { Column }\end{array}$ & \begin{tabular}{|l} 
Aerosol \\
Mixing State
\end{tabular} & $\begin{array}{l}\text { Lensing } \\
\text { Effect }\end{array}$ & Surface Albedo \\
\hline $\begin{array}{l}\text { Base J-value } \\
\text { lookup table } \\
\text { in MACH }\end{array}$ & Climatology & Climatology & $\begin{array}{l}\text { Constant } \\
\text { Climatology } \\
\text { (Peterson } \\
\text { (1976) }\end{array}$ & $\begin{array}{l}\text { Homogeneous } \\
\text { Mixture for } \\
\text { Aerosols }\end{array}$ & No & $\begin{array}{l}290-400 \mathrm{~nm}(0.05) \\
400-450 \mathrm{~nm}(0.06) \\
450-500 \mathrm{~nm}(0.08) \\
500-550 \mathrm{~nm}(0.1) \\
550-600 \mathrm{~nm}(0.11) \\
600-640 \mathrm{~nm}(0.12) \\
640-660 \mathrm{~nm}(0.135) \\
660-700 \mathrm{~nm}(0.15) \\
\text { (Peters on }(1976) \\
\end{array}$ \\
\hline $\begin{array}{l}\text { Base } \\
\text { MESSy- } \\
\text { JVAL in } \\
\text { MACH }\end{array}$ & $\begin{array}{l}\text { Climatology } \\
\text { (Chen et al., } \\
\text { 2020) }\end{array}$ & $\begin{array}{l}\text { Climatology( } \\
\text { Chen et al., } \\
\text { 2020) }\end{array}$ & Online & $\begin{array}{l}\text { Homogeneous } \\
\text { Mixture for } \\
\text { Aerosols }\end{array}$ & No & Online \\
\hline $\begin{array}{l}\text { Revised } \\
\text { MESSy- } \\
\text { JVAL in } \\
\text { MACH }\end{array}$ & $\begin{array}{l}\text { Online (This } \\
\text { Work) }\end{array}$ & $\begin{array}{l}\text { Online (This } \\
\text { Work) }\end{array}$ & Online & $\begin{array}{l}\text { Externally } \\
\text { Mixed + } \\
\text { Internally } \\
\text { Mixed } \\
\text { Aerosols + } \\
\text { Core-Shell } \\
\text { Black Carbon } \\
\text { (This Work) }\end{array}$ & $\begin{array}{l}\text { Yes } \\
\text { (This } \\
\text { Work) }\end{array}$ & Online \\
\hline $\begin{array}{l}\text { Base } \\
\text { radiative } \\
\text { transfer in } \\
\text { GEM }\end{array}$ & Climatology & Climatology & Online & $\begin{array}{l}\text { Homogeneous } \\
\text { Mixture for } \\
\text { Aerosols }\end{array}$ & No & Online \\
\hline $\begin{array}{l}\text { Revised } \\
\text { radiative } \\
\text { transfer in } \\
\text { GEM }\end{array}$ & $\begin{array}{l}\text { Online } \\
\text { (Makar et al., } \\
2015 \mathrm{a}, \mathrm{b} \text { ) }\end{array}$ & $\begin{array}{l}\text { Online } \\
\text { (Makar et al., } \\
2015 \text { a, b) }\end{array}$ & Online & $\begin{array}{l}\text { Homogeneous } \\
\text { Mixture for } \\
\text { Aerosols }\end{array}$ & No & Online \\
\hline
\end{tabular}

Table 1: Aerosol optical calculations in GEM and MACH.

170 The calculations of aerosol optical depth, single-scattering albedo, and asymmetry factor used by the GEM weather forecast model, also us ed in the offline version of the radiative transfer module in GEM-MACH (Liand Barker, 2005) with no-feedback configuration, are based on a climatology produced by Toon and Pollack (1976), with specified aerosol loading for continents and oceans, a maximum value at the Equator and a decrease towards the poles. The solar absorption properties are only 
as sumed to be affected by aerosols in the clear-sky atmosphere (Markovic et al.,2008). In contrast, the on-line version of the radiative transfer module in the feedback-enabled version of GEM-MACH makes use of a homogeneous aerosol mixture Mie scattering (Bohren and Huffman, 1983) code for meteorological radiative transfer calculations, and the model-generated aerosols in the feedback mode (Makar et al., 2015 a, b) are used for radiative transfer calculations.

The new photolysis module in GEM-MACH (MESSy-JVAL) is based on JVAL14-MESSy of Sander et al. (2014). The photolysis module JVAL was adapted by Sander et al. as a module inside the Modular Earth Sub-model System (MESSy) interface of Jöckel et al. (2005). The original formulation of photolysis rates calculations was developed by Landgraf and Crutzen (1998) and has been since adopted in several atmospheric models (Sander et al., 2014). The actinic flux calculations include the effects of aerosols and clouds on photolysis rates. The optical data for cloud scattering and absorption are adopted from Slingo (1989) (Sander et al., 2011a). The previous off-line application of MESSy-JVAL in GEM-MACH (Chen et al, 2020), made use of a climatology of aerosol concentration (a constant aerosol vertical profile above land and a different vertical profile over water). Cloud radiative properties and cloud fraction were calculated online at runtime (Chen et al., 2020). The focus of this study is to improve the representation of aerosol optical properties in MESSy-JVAL, and to determine their impact on model performance.

In the following sections, we describe the methods we used to improve the representation of aerosol optical properties in MESSy-JVAL, followed by the evaluations of the improved photolysis module and the limitations of the model in photolysis rate calculations. Section 2 provides a description of the model configuration, simulation setup and the observations used to evaluate the model output, calculations of the new lookup table for aerosol optical properties, and a description of the revised photolysis rate calculations in GEM-MACH. The comparis on of the updated MESSy-JVAL with the base off-line version is presented in section 3, followed by the results of different evaluations of the improved photolysis module: comparisons with observations, evaluations of the impacts of AOD calculations and model-generated aerosols on the photolysis rates calculations, and a case study of photolysis calculations under high pollutant flux emissions conditions. Summary and conclusions of this study are presented in Section 4.

\section{Methods}

\subsection{Overview}

In order to improve the photolysis module and calculate aerosol feedbacks more accurately, we developed a new Mie lookup table for aerosoloptical properties which was accessed within the improved version of MESSy-JVAL. An initial lookup table was calculated using the refractive indices of six representative aerosol components and the Mie scattering code within the VECTOR model(McLinden et al., 2002). Using the hygroscopic growth factor of each aerosol type, we calculated the dry size parameter (Section 2.2, equation1 of the initial lookup table, which was then interpolated into GEM-MACH dry size parameter to calculate the final lookup table as a function of GEM-MACH particle size bins and wavelengths. The calculated aerosol composition and size in GEM-MACH was used as input for photolysis ratecalculations, and a hybrid aerosol mixing state was 
as sumed for size bins containing different concentrations of black carbon to calculate the optical properties of four aerosol categories: black carbon, sea-salt, dustand other internally mixed components.

Currently, there is a size-resolved (sectional) representation of atmospheric aerosol particles in GEM-MACH, which may be used for determining the impact of aerosol feedbacks on radiation and photoly sis. When GEM-MACH's aerosol feedbacks are enabled, the aerosol direct effect makes use of a Mie scattering approach and the assumption of a binary mixture between dry aerosols and water for the complex refractive index(Makar et al., 2015a). For photolysis calculations as carried out here, we made use of GEM-MACH's calculated aerosol composition and size as input for photolysis rate calculations. The new algorithm uses the eight dry chemical components of GEM-MACH aerosol (sulfate, nitrate, ammonium, primary organic matter, secondary organic matter, black carbon, dust and sea-salt) and reads in the data from the updated lookup table (see sections 2.2, 2.3, following) to calculate the scattering and absorption optical depth and asymmetry factor of black carbon, seasalt, dust and other internally mixed components. We used the black carbon particle size in GEM-MACH as an indicator of the mixing state of the internally mixed particles. For each GEM-MACH size bin, the mas s fraction of black carbon to the total mass of all the other particles in that bin was calculated. Since the externally-mixed black carbon particles are most common near combustion sources, if a GEM-MACH particle size bin contains a black carbon mas s fraction that is near or larger than that of a typical combu stion emission particle (theblack carbon mas s fraction of more than $40 \%$ (Stevens and Dastoor, 2019), the particle bin was considered to be mostly black carbon, no absorption amplification factor was applied to black carbon photolysis rate calculations, and an external particle mixing state for that size bin was assumed (i.e., black carbon as a separate particle, and a volume-averaged homogeneously mixture of ammonium sulfate, ammonium nitrate, primary and secondary organics). If the black carbon mass fraction for a particle size bin was less than $40 \%$, we as sumed that black carbon is coated with other internal particle components, and a core-shell configuration was used for that size bin; the black carbon forms a core and other internal particle components (primary and secondary organic matter, ammonium sulfate, and ammonium nitrate), form a shell. In this case, the black carbon is mixed with other condensed or coagulated components, the bin is more aged, and we apply a lensing correction factor to the black carbon absorption efficiency recommended by Bond et al. (2006). It should be noted that sea salt and dust were not included in the assumptions of the internally mixed particles, and in both cases mentioned above, those aerosols were considered as separate particles. These underlying assumptions were used for the calculations of the aerosol optical properties for four independent aerosol groups: sea-salt, dust, black carbon and the internally mixed particles (See Fig. 1). We describe our methodology in more detail in the following sections.

\subsection{Developing a new aerosol optical properties look-up table for MESSy}

In order to update the aerosol effects in the MESSy photolysis module in GEM-MACH, we calculated a new lookupusing the

Mie scattering code within the VECTOR model (McLinden et al., 2002) for extinction efficiency, single scatter albedo and asymmetry factor for six aerosol types, which within the lookup table are treated as pure-composition particles of sea-salt, black carbon, dust, ammonium sulfate, ammoniu mnitrate and organic carbon. The initial version of the new lookup table was calculated for single components, each with its own water uptake properties derived fromthe literature. One dimension of the 
table is the wet particle radius range for a log arithmically expanding set of cut-sizes of the aerosol dis tribution of GEM-MACH (0-10, 10-20, 20-40, 40-80, 80-160, 160-320, 320-640, 640-1280, 1280-2560, 2560-5120, 5120-10240, and 10240-20480 nm), five wavelengths $(200,300,400,600,1000 \mathrm{~nm})$ and seven differentrelativehumidity levels $(0 \%, 50 \%, 70 \%, 80 \%, 90 \%, 95 \%$, $98 \%, 99 \%$ ) for all aerosols except dust, which was assumed to have no water uptake. The effective wet particle radii were calculated based on a power-law distribution (Hansen and Travis, 1974) of each particle range. The relative humidity determines the water fraction for all other aerosol types. The selection of wider spacing at lower relative humidity and longer wavelength was due to the growing dependency of optical properties to increasing relative humidity and decreasing wavelengths. We assumed a flat distribution of aerosol radii within each bin size. The complexrefractive indices of the watersoluble inorganic aerosols, namely ammonium sulfate, ammonium nitrate and sea salt were calculated using the FORTRAN software developed by Andrew Lacis (https://www.giss.nasa.gov/staff/mmishchenko/ftpcode/lacis/lacis_refrac.rhwmri.f) which has been used in many recent studies (Jeong, 2020; Bozzo et al., 2020; Escribano et al., 2014; Schuster et al., 2009). In this model, all aeros ols are treated as homogeneous mixtures. Parametric formulas are derived for the changes in the real part of the refractive index, specific density, size, and water activity as functions of mass fraction. These formulas are used to interpolate spectrally between the refractive indices of dry ammonium sulfate, sea salt, and ammonium nitrate and those of water. For ammonium sulfate, the complex refractive indexis from Toon et al. (1976). The water activity for this aerosol type is based on Tang and Munkelwitz(1994). For ammonium nitrate, the real and imaginary parts of the refractive index are from Tang et al. (1981) and Gosse et al. (1997), and the water uptake is from Tang (1996). The complex refractive index of sea salt is based on Shettle and Fenn (1979), which relies on Dorsey (1940).

For dust, no water uptake has been assumed, and thus no dependency on the relative humidity. The complexrefractive index of dust is assumed to be independent of particle size and is obtained from the VECTOR model's library of refractive indices with the real part of the dust refractive index varying between 1.55 and 1.57 and the imaginary component increasing monotonically from $0.004 \mathrm{i}$ at $1000 \mathrm{~nm}$ to $0.025 \mathrm{i}$ at $200 \mathrm{~nm}$. For organic carbon, the complexrefractive index is wavelengthdependent for all relative humidities and was extracted from Fast-JX, the photolysis mechanismused in GEOS-CHEM (Goddard Earth Observing System(GEOS) of the NASA Global Modeling and Assimilation Office). Fast-JX v7.0 calculates aerosol extinction efficiencies at five wavelengths, 200, 300, 400, 600 and 999nm. The file jv_spec_mie.dat (http://rain.ucis.dal.ca/ctm/CHEM_INPUTS/FAST_JX/v2020-02/jv_spec_mie.dat) in Fast-JX v7.0 contains the quantum yields and aerosol cross sections for photolysis. Real and imaginary parts of the refractive index of organic carbon at $98 \%$ were obtained by linear interpolation between the indices at RHs of 95 and 99\%. For black carbon, the dependence on relative humidity was based on hyg roscopic growth factors (HGF; the ratio of the wet particle radius to the dry particle radius) obtained from Lei et al. (2014) (Table 2). The RH-dependent refractive index $\left(\mathrm{n}_{\mathrm{RH}}\right)$ is a $\mathrm{HGF}^{3}$-weighted mean of refractive indices of pure black carbon $\left(\mathrm{n}_{\mathrm{BC}}\right)$ and pure water $\left(\mathrm{n}_{\mathrm{water}}\right)$ :

$\mathrm{n}_{\mathrm{RH}}=\left[\left(\mathrm{HGF}_{\mathrm{RH}}^{3}-1\right) \mathrm{n}_{\text {water }}+\mathrm{n}_{\mathrm{BC}}\right] / \mathrm{HGF}_{\mathrm{RH}}^{3}$

with water having a spectrally constant refractiveindex of 1.333 (with no imaginary component over the relevant wavelength range) and pure black carbon having a spectrally constant refractive index of 1.75 - 0.44i (Kou, 1996). In order to employ the 
new lookup table in GEM-MACH, we developed a stand-aloneFORTRAN code to interpolate the optical properties of aerosols into GEM-MACH wavelengths and size bins. The output of this off-line program was used as the new lookup table for the improved version of the photoly sis code discussed in this study. Here we provide a brief description of the methods we used in our calculations.

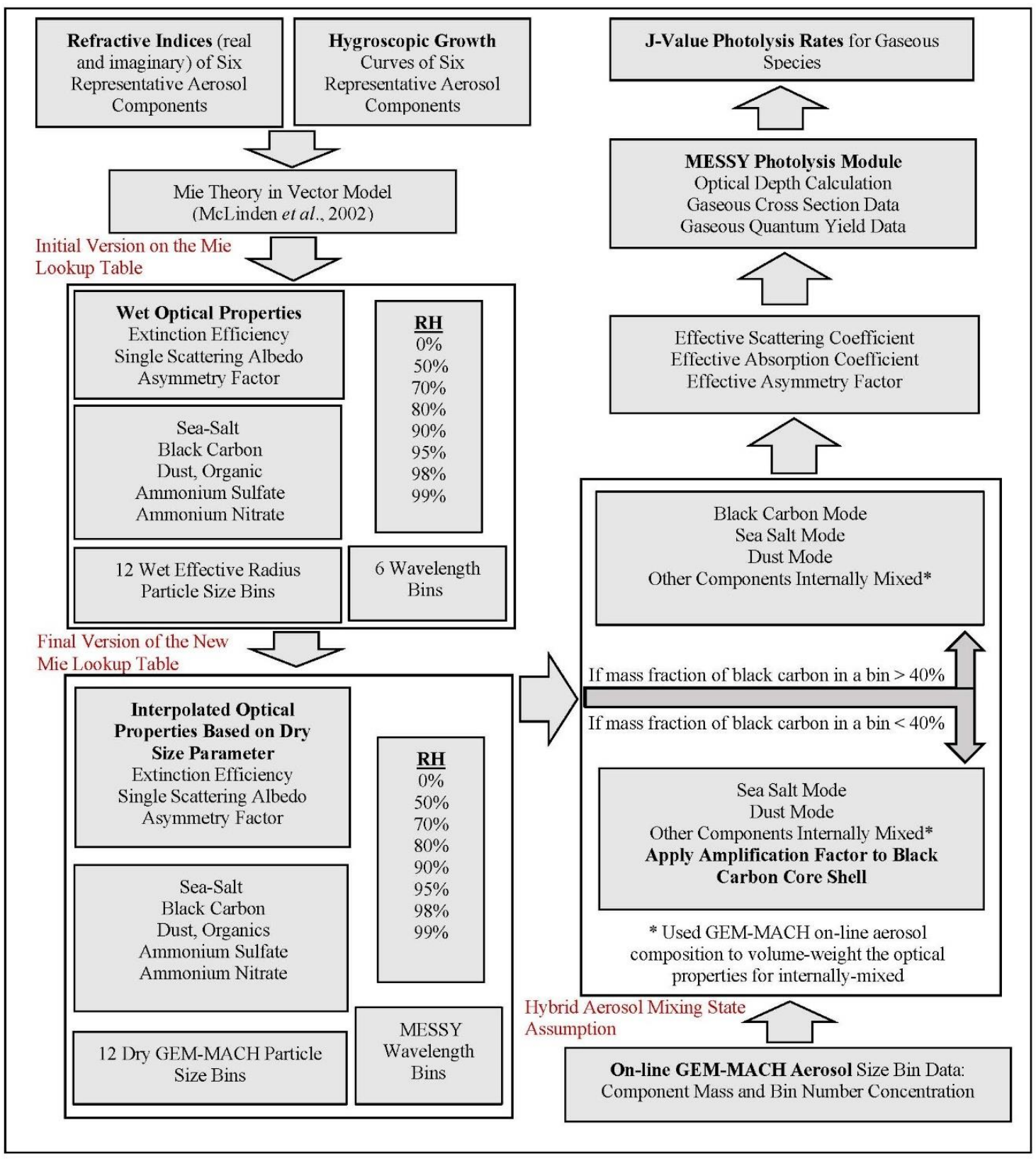

Figure 1: Steps and me thods in calculating the new Mie lookup table for photolysis rates in GEM-MACH. RH represents the relative $h$ umidity and $\lambda$ is the wavelength. 
Since the initial version of the new lookup table was calculated based on wet particle sizes, we used the hy groscopic growth factor of each aerosol type (Laskina et al., 2015, Ting et al., 2017, Zamora et al., 2013, and SOA is based on GEOS-Chem optical lookup table,jv_spec_mie.dat) at each relative humidity and the wet radius of each particle type, to calculate the dry aeros ol radius size.

\begin{tabular}{|l|l|}
\hline RH (\%) & HGF \\
\hline 99 & 1.066 \\
\hline 98 & 1.062 \\
\hline 95 & 1.05 \\
\hline 90 & 1.03 \\
\hline 80 & 1.02 \\
\hline 70 & 1.01 \\
\hline 50 & 1 \\
\hline 0 & 1 \\
\hline
\end{tabular}

Table 2: Hygroscopic growth factors (HGF) for black carbon (based on Lei et al., 2014).

Using the dry radius size and the wavelengths in the initial lookup table (200, 300, 400, 600, $1000 \mathrm{~nm})$, the initial size parameter was calculated using:

$\alpha_{i}=\frac{2 \pi r_{i}}{\lambda_{i}}$

where $\alpha_{i}$ is the initial size parameter, $r_{i}$ is the dry radius of the particle, and $\lambda_{i}$ is the wavelength in the initial lookup table.

Using the same formula, the size parameter for the final lookup table was calculated based on GEM-MACH average dry particle size bins $(7.5 \mathrm{~nm}, 15 . \mathrm{nm}, 30 . \mathrm{nm}, 60 . \mathrm{nm}, 120 . \mathrm{nm}, 240 . \mathrm{nm}, 480 . \mathrm{nm}, 960 . \mathrm{nm}, 1920 . \mathrm{nm}, 3840 . \mathrm{nm}, 7680 . \mathrm{nm}$ and 15360. nm) and wavelengths (205 nm, $287 \mathrm{~nm}, 302 \mathrm{~nm}, 309 \mathrm{~nm}, 320 \mathrm{~nm}, 370 \mathrm{~nm}$ and $580 \mathrm{~nm})$. The final lookup table components as a function of particle size, were calculated by linear interpolation of GEM-MACH size parameter from the size parametervalues in the initial version of thenew lookup table (see Fig. 1). The initial and interpolated extinction efficiency of ammonium sulfate versus dry aerosol size parameter is illustrated in Fig. 2. The final interpolated lookup table of extinction efficiency, single scatter albedo and as ymmetry factor was used to calculate the absorption and scattering cross section and as ymmetry factor of seven pure aerosol types (sea-salt, black carbon, dust, ammonium sulfate, ammonium nitrate, primary organic carbon and secondary organic carbon) in GEM-MACH. The data in the lookup table is sorted by increasing size parametervalues (based on the dry aerosol sizes) for each aerosol type and relative humidity, i.e., the optical properties in the lookup table depend on the water uptake for the given relativehumidity. 

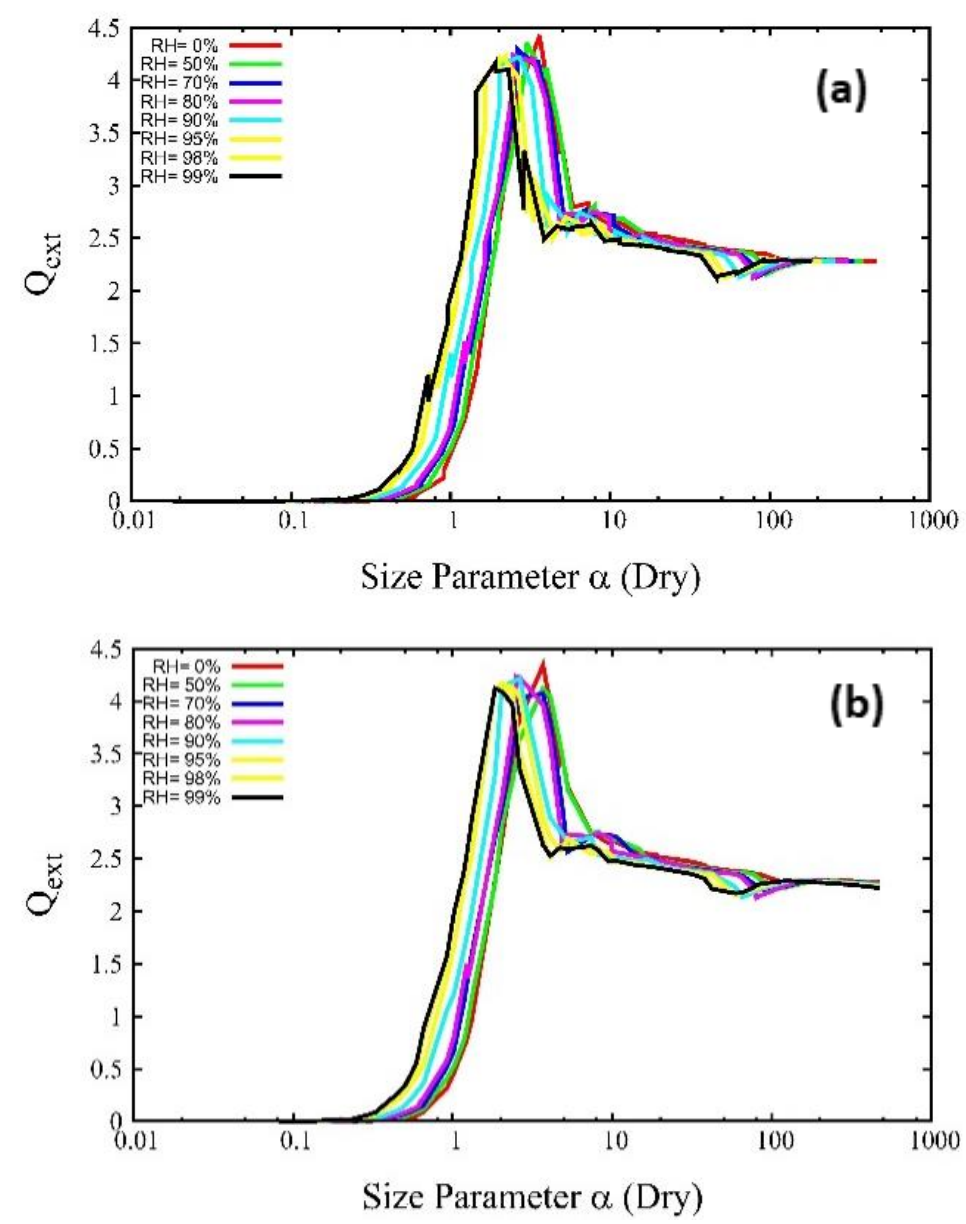

Figure 2: : (a) Initial and (b) interpolated $Q_{\text {ext }}$ (Extinction efficiency) vs dry $\alpha$ (Size Parameter) for Ammonium Sulfate

\subsection{Updating the photolysis module in the GEM-MACH in-line chemical transport model:}

305 After calculating the new lookup table, we modified the MESSy-JVAL code to use the new lookup table, along with the calculated aerosol composition and size by GEM-MACH, as input for photoly sis rate calculations. The new updated code uses the eight dry chemical components of GEM-MACH aerosol feedback (sulfate, nitrate, ammonium, black carbon, primary org anic matter, secondary organic matter, dust and sea-salt) and the data in the updated lookup table to calculate scattering and absorption optical depth and asymmetry factor of black carbon, sea-salt, dust and other internally mixed components. The volume concentration of each aerosol ty pe ( $\mathrm{m}^{3}$ of each aerosol per $\mathrm{m}^{3}$ of air) was calculated using the GEM-MACH predicted mass concentration of each aerosol type $\left(\mu \mathrm{g} \mathrm{kg}^{-1}\right)$. The number concentration of each aerosol (number of aerosols per $1 \mathrm{~m}^{3}$ of air) was calculated by dividing the volume concentration of the aerosol by the volume of each size bin. We used the predicted 
mas s concentration of nitrate in GEM-MACH, and the molecular weight of ammonium nitrate to calculate the mass concentration of ammonium nitrate. Finally, to conserve the mass of ammonium, and since ammonium sulfate, ammonium bisulfate and letovicite have very similar refraction indices, the remaining mass of ammoniumand the mas s concentration of sulfate were used to calculate the mass concentration of ammonium sulfate.

In order to implement the core-shell parameterization where the mass fraction of black carbon is less than $40 \%$ in a particle bin in GEM-MACH, we calculated the number of particles with a black carbon core $\left(\mathrm{N}_{\mathrm{BC}}\right)$, and the mas s concentration of black carbon $\left(\mathrm{M}_{\mathrm{BC}}\right)$ for those specific size bins. Using the two values, the dry black carbon core size was calculated as follows:

where $r_{B C}$ is the dry radius of the black carbon core of a particle and $\rho_{\mathrm{BC}}$ is the density of black carbon ("void-freeblack carbon core density of $1.8 \mathrm{~g} \mathrm{~cm}^{-3}$ (McMeeking et al., 2010)"). The total wet radius of a core-shell particle was calculated using the volume-weighted hygroscopic growth factor of the components in the core-shell particle and the total wet radius of the core (black carbon) and shell (secondary org anics, ammoniumsulfate and ammoniumnitrate) in that particle. This information was used to calculate the size parameter of the black carbon core $\left(\alpha_{b c}\right)$ and the total particle size parameter $\left(\alpha_{\text {total }}\right)$. The absorption amplification factor for the case of black carbon core-shell, was calculated using the core-shell parameterization by Bond et al. (2006). with the observationally-constrained maximum threshold of 1.93 (Bond et al., 2006). As described below, these parameters are used to provide an amplification factor based on previous core-shell Mie scattering calculations carried out by Bond et al., (2006).

330 Sea-salt, dust and black carbon (when its mas s fraction was $>40 \%$ ) aerosols were as sumed to be externally mixed at all times - their effective scattering coefficient $\left(\mathrm{sca}_{\mathrm{c}}\right)$, absorption coefficient $\left(\mathrm{abs}_{c}\right)$ and asymmetry factors $\left(\operatorname{asym}_{\mathrm{c}}\right)$ of each of these aerosols were calculated using the elements of the lookup table and GEM-MACH's predicted concentrations for these aerosol species:

$\mathrm{sca}_{\mathrm{c}}=\sum_{\mathrm{i}=1}^{12} \mathrm{Q}_{\mathrm{ext}_{\mathrm{i}}} \times \mathrm{ssa}_{\mathrm{i}} \times \mathrm{N}_{\mathrm{i}} \times \pi \times \mathrm{r}_{\mathrm{i}}^{2}$

$\operatorname{abs}_{c}=\sum_{\mathrm{i}=1}^{12} \mathrm{Q}_{\mathrm{ext}_{\mathrm{i}}} \times\left(1-\mathrm{ssa}_{\mathrm{i}}\right) \times \mathrm{N}_{\mathrm{i}} \times \pi \times \mathrm{r}_{\mathrm{i}}^{2}$

$\operatorname{asym}_{\mathrm{c}}=\sum_{\mathrm{i}=1}^{12} \mathrm{ag}_{\mathrm{i}} \times \mathrm{mf}_{\mathrm{i}}$

where subscript $\mathrm{c}$ denotes each aerosol category, for each size bin (i) in GEM-MACH ( $\mathrm{i}=1$ to 12 ), $\mathrm{Q}_{\text {ext }}$ is the extinction efficiency of each aerosol type, $N_{i}$ is the number concentration of each aerosol type $\left(\mathrm{cm}^{-3}\right), r_{i}$ is the radius of bin $i(\mathrm{~cm}), s s a_{i}$ is single scatter albedo of each aerosol type, ag is the asymmetry factor, and $\mathrm{mf}_{\mathrm{i}}$ is the fraction of the mass concentration of each aerosol type to the total mass concen tration of all particles (the asymmetry factor was weighted by mas s fraction for pure particles ). In the case where the mas s fraction of black carbon for a particle size bin was les s than $40 \%$, the effective scattering and absorption coefficient of black carbon was calculated using: 


$$
\begin{aligned}
& \mathrm{sca}_{\mathrm{bc}}=\sum_{\mathrm{i}=1}^{12} \mathrm{Q}_{\mathrm{ext}_{\mathrm{i}}} \times \mathrm{ssa}_{\mathrm{i}} \times \mathrm{N}_{\mathrm{i}} \times \pi \times \mathrm{r}_{\mathrm{bc}}^{2} \\
& a b s_{b c}=\sum_{i=1}^{12} Q_{\text {ext }_{i}} \times\left(1-s s a_{i}\right) \times N_{i} \times \pi \times r_{b c}^{2} \times a m p
\end{aligned}
$$

where $\mathrm{r}_{\mathrm{BC}}$ is the radius of black carbon core particle and $a m p$ is the absorption amplification factor by Bond et al. (2006), based on the black carbon core and shell size parameters. For the fourth aerosol category in each GEM-MACH size bin (volume-averaged internally mixed particles), we calculated the volume fraction(vf) of each component (ammoniumsulfate, ammonium nitrate, primary and secondary org anics) to the total volume of the internally mixed particles:

$v i_{(\mathrm{IM})}=v i_{(\mathrm{AS})}+v i_{(\mathrm{AN})}+v i_{(\mathrm{OC})}+\mathrm{vi}_{(\mathrm{PC})}$

$\mathrm{vf}_{\mathrm{AS}}=\frac{\mathrm{vi}_{(\mathrm{AS})}}{\mathrm{vi}_{(\mathrm{IM})}}, \quad \mathrm{vf}_{\mathrm{AN}}=\frac{\mathrm{vi}_{(\mathrm{AN})}}{\mathrm{vi}_{(\mathrm{IM})}}, \quad \mathrm{vf}_{\mathrm{OC}}=\frac{\mathrm{vi}_{(\mathrm{OC})}}{\mathrm{vi}_{(\mathrm{IM})}}, \quad \mathrm{vf}_{\mathrm{PC}}=\frac{\mathrm{vi}_{(\mathrm{PC})}}{\mathrm{vi}_{(\mathrm{IM})}}$

where vi is the volume concentration of each aerosol in the internally mixed particles, IM stands for the internally mixed particles, $\mathrm{AS}$ is ammonium sulfate, $\mathrm{AN}$ is ammonium nitrate, $\mathrm{OC}$ is secondary organic matter, and $\mathrm{PC}$ is primary organic matter. Equations 11 to 13 were used to calculate the effective s cattering and absorption coefficients and asymmetry factor of internally mixed particles:

$$
\begin{aligned}
& \operatorname{sca}_{\mathrm{c}}=\sum_{\mathrm{i}=1}^{12} \sum_{\mathrm{j}=1}^{4} \mathrm{Q}_{\mathrm{ext}_{\mathrm{i}, \mathrm{j}}} \times \mathrm{ssa}_{\mathrm{i}, \mathrm{j}} \times \mathrm{vf}_{\mathrm{i}, \mathrm{j}} \times \mathrm{N}_{\mathrm{i}} \times \pi \times \mathrm{r}_{\mathrm{i}}^{2} \\
& \operatorname{abs}_{\mathrm{c}}=\sum_{\mathrm{i}=1}^{12} \sum_{\mathrm{j}=1}^{4} \mathrm{Q}_{\mathrm{ext}_{\mathrm{i}, \mathrm{j}}} \times\left(1-\mathrm{ssa}_{\mathrm{i}, \mathrm{j}}\right) \times \mathrm{vf}_{\mathrm{i}, \mathrm{j}} \times \mathrm{N}_{\mathrm{i}} \times \pi \times \mathrm{r}_{\mathrm{i}}^{2} \\
& \operatorname{asym}_{c}=\sum_{i=1}^{12} \sum_{j=1}^{4} a g_{i, j} \times v f_{i, j} \times m f_{i}
\end{aligned}
$$

where the indices $(j=1,2,3,4)$ corres pond to the aerosol type inside the internally mixed particles (ammonium sulfate, ammonium nitrate, second ary org anic carbon, primary organic carbon). Note that the calculations using equations 4 to 8 and 11 to 13 were done for each horizontal grid-point, vertical level, wavelength and relative humidity.

We performed a linear interpolation of the relative humidity in the lookup table for all the aerosol types, with the exception of dust aerosol (which had no water uptake), to calculate the scattering and absorption coefficients at each given relative humidity in GEM-MACH. Scattering and absorption optical depth for each model layer and aerosol category were calculated by the following formula:

$\tau_{\text {sca }}=$ sca $_{\mathrm{c}} \times \mathrm{dz}$

$\tau_{\mathrm{abs}}=\mathrm{abs}_{\mathrm{c}} \times \mathrm{dz}$

where $\tau_{\text {sca }}$ and $\tau_{\text {sca }}$ are the scattering and absorption optical depth of each aerosol category and $\mathrm{dz}$ is the vertical level thickness. The total scattering and absorption optical depth at each vert ical level for each aeros ol category (black carbon, seasalt, dust and internally mixed particles) was calculated using: 
$\tau_{\mathrm{abs}}=\mathrm{abs}_{\mathrm{c}} \times \mathrm{dz}$

Total $\left(\tau_{\mathrm{abs}}\right)=\sum_{\mathrm{c}=1}^{4} \tau_{\mathrm{abs}_{\mathrm{c}}}$

$\operatorname{Total}($ asym $)=\sum_{c=1}^{4} \frac{\tau_{\text {scac }}}{\operatorname{Total}\left(\tau_{\text {sca }}\right)} \operatorname{asym}_{c}$

In the above summations, c represents each aerosol category. Integrating the total scattering and absorption optical depth through the entire column at each grid-point and for each wavelength $(\lambda)$, gives the total modelled AOD at that wavelength. This information was used to calculate $\mathrm{J}$-values for photolysis reactions depending on the attenuation of the radiation stream by particles.

\subsection{Simulation Setupand Emissions}

For this study, we used GEM-MACH v2.4, with 12-bin average size distribution of particles, and online aerosol feedbacks between weather and air-quality (Makar et al., 2015a, b). The model domain covers most of continental Canada and United States with a horizontal grid-spacing of $10 \mathrm{~km}, 80$ hybrid vertical levels with a model top at $0.1 \mathrm{hPa}, 15$-minute operator splitting time step and a 1-hour output time step (Fig. 3). The meteorological initial and boundary conditions for our $10 \mathrm{~km}$ horizontal resolution simulations were from the operational Regional Deterministic Prediction System, ECCC's operational numerical weather predictions system (RDPS, Caron and Anselmo, 2014). The chemical boundary conditions are 3-month mean climatology from the global chemical transport model MOZART-4 ("The Model for Ozone and Related chemical

Tracers, version 4 (Emmons et al., 2010)").

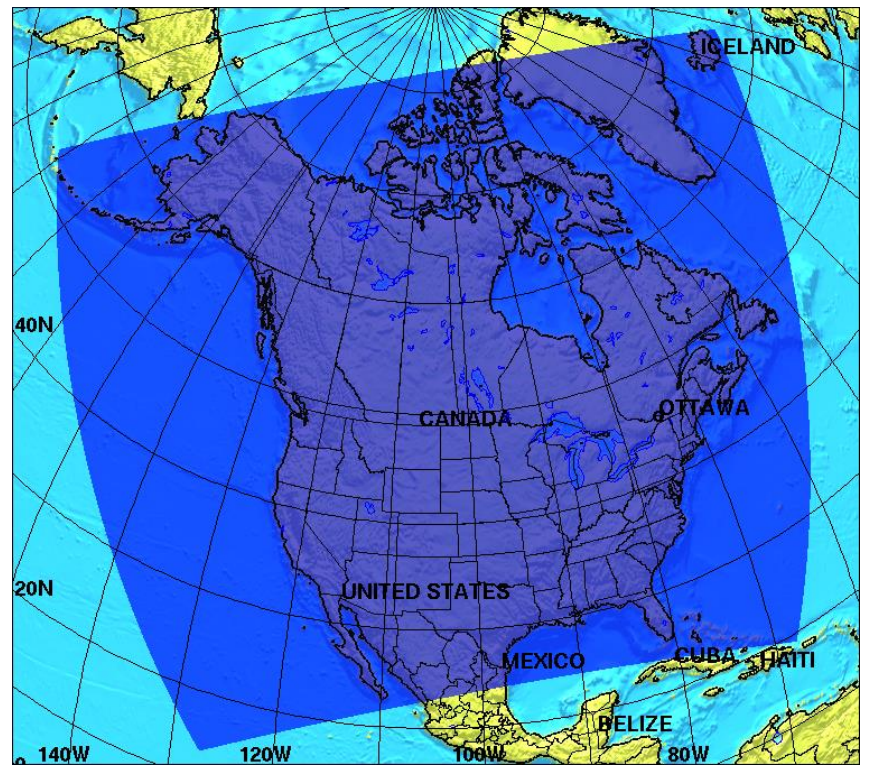

Figure 3: GEM-MACH model North American domain, with $10 \mathrm{~km} \times 10 \mathrm{~km}$ horizontal grid resolution. 
The Canadian anthropogenic emissions used in our simulations were obtained from the Canadian Air Pollutant Emissions Inventory (APEI, 2021), including the 2015 Canadian area and point source e mis sions and 2013 Canadian transportation (onroad and off-road) emissions. A projected 2017 US anthropogenic emissions inventory was obtained from the U.S. Environmental Protection Agency (EPA) 2011 Air Emissions Modelling Version 6.3 Platform (https://www.epa.gov/airemissions-modeling/2011-version-63-platform; Eyth et al., 2013) and the 2008 Mexican inventory was obtained from the EPA's 2011 Air Emission Modelling Version 6.2 Platform (https://www.epa.gov/air-emis sions-modeling/2011-version-62platform). The SMOKE emissions processing system (https://cmascenter.org/smoke/) was used to prepare hourly gridded emissions files for GEM-MACH from these three national annual inventories. The North American wild fire emis sions for the 2018 fire seas on were produced by the Canadian Forest Fire Emissions Prediction System, (CFFEPS), developed by the Canadian Forest Service (CFS) of Natural Resources Canada (Anderson et al., 2019). The CFFEPS model consists of a firegrowth model, a fire emissions model and a thermodynamic model to calculate fuel consumption, fire energy, the height of a smoke plume and emis sions (Anderson et al., 2011; Chen et al., 2019). CFFEPS uses the Canadian Forest Fire Danger Rating System(CFFDRS), including the Canadian Fire Weather Index (FWI) System(Van Wagner, 1987) to provide input dataon fuel moisture, and the Canadian Forest Fire Behaviour Prediction (FBP) System(Fores try Canada Fire Danger Group, 1992) for predictions of surface, crown and total fuel consumption. Smoke emis sions input data for CFFEPS are collected by the Canadian Wildland Fire Information System (CWFIS) (Lee et al., 2002). The model has been integrated into the ECCC FireW ork air quality forecast system (Pavlovic et al., 2016) and has been operational since May 2019. The CFFEPS v2.03 code is available from: https ://doi.org/10.5281/zenodo.2579383 (Anders on et al., 2019).

\subsection{Observations}

Satellite data from Terra MODIS (MODerate resolution Imaging Spectroradiometer) level-3 atmospheric gridded data (Platnick et al.,2015), the MERRA-2 re-analys is (Modern-Era Retrospective analysis for Research and Applications - Version 2, Global Modeling and Assimilation Office, 2015) and AERONET (Aerosol Robotic Network) ground-based measurements, were used in this study to to evaluate the modifications in the photoly sis module in GEM-MACH.

NASA's Terra and Aqua satellite are in polarorbits. The MODIS ins trument operates on both Terra and Aqua and has a global coverage of every one to two days in 36 spectral bands between 0.405 to $14.385 \mu \mathrm{m}$. For the purpose of this study, we used Terra MODIS level-3 Atmos pheric Daily Global Product of AOD with 1-degree s patial resolution at $550 \mathrm{~nm}$ (obtained from the Goddard Earth Sciences Data and Information Services Centre, GIOVANNI platform 415 https://giovanni.gsfc.nasa.gov/giovanni/). The MERRA-2 atmos pheric reanalysis assimilation system produced by NASA's Global Modeling and Assimilation Office (GMAO) is the second and updated version of the original MERRA atmospheric reanalysis (Rienecker et al., 2011, Gelaro et al., 2017). MERRA-2 includes aerosol reanalysis using the Goddard Earth Observing System version 5 (GEOS-5) coupled with the Goddard Chemistry, Aerosol, Radiation, and Transport model (GOCART; Chin et al., 2002; Colarco et al., 2010). It uses the Goddard Aerosol Assimilation System(GAAS) along with 
3 hours by MERRA-2 into GEOS-5/GOCART modeling system (Randles, et al., 2017). The MERRA-2 re-analysis products use several satellite and ground-based measurement data, including MODIS Aqua and Terra, MISR and AERONET measurements. The monthly MERRA-2 Aerosol Optical Depth Analysis V5.12.4 data in this study (DOI: 10.5067/XOGNBQEPLUC5), and the hourly MERRA-2 Aerosol Scattering AOT (DOI: 10.5067/KLICLTZ8EM9D) were obtained from the Goddard Earth Sciences Data and Information Services Centre (GIOVANNI: https://giovanni.gsfc.nasa.gov/giovanni/) platform, with a spatial resolution of $0.625^{\circ} \times 0.5^{\circ}$ longitude-by-latitude.

For ground-based measurements, we used quality assured AERONET Sun photometer measurements of AOD at $500 \mathrm{~nm}$ for North American sites (Fig. 4). The Sun triplet meas urements are performed every 15 minutes for older model 4 instruments and every 3 minutes for newer model 5 and CE318-T instruments (Giles et al., 2019). The AERONET data used in this study is cloud screened according to the AERONET V3 algorithmdescribed in Giles et el. (2019). We used the AngstromExponents provided by the sun photometer within AERONET data to evaluate the model AOD at $580 \mathrm{~nm}$. The Ang stromexponent (AE) represents the wavelength $(\lambda)$ dependency of AOD, provides basic information about the size dis tribution of aerosols and is calculated by the following formula:

$\mathrm{AE}=-\frac{\mathrm{d} \ln (\mathrm{AOD})}{\mathrm{d} \ln (\lambda)}$

To calculate AOD at $580 \mathrm{~nm}$, we used a variation of the above formu la:

$\frac{A O D_{1}}{A O D_{2}}=\left(\frac{\lambda_{1}}{\lambda_{2}}\right)^{-A E}$

where $\mathrm{AOD}_{1}$ and $\mathrm{AOD}_{2}$ are the aerosoloptical depth at 500 and $580 \mathrm{~nm}$, and $\lambda_{1}$ and $\lambda_{2}$ are $500 \mathrm{~nm}$ and $580 \mathrm{~nm}$ wavelengths respectively. We used (440 nm - $675 \mathrm{~nm})$ Angstrom Exponent to obtain the observed AOD at $580 \mathrm{~nm}$, which was used to compare with GEM-MACH output AOD calculated as described in section 2.3.

\begin{tabular}{|c|l|c|c|c|}
\hline Simulation Name & \multicolumn{1}{|c|}{ Date } & $\begin{array}{c}\text { Improved MESSy- } \\
\text { JVAL }\end{array}$ & $\begin{array}{c}\text { Aerosol } \\
\text { Feedback }\end{array}$ & AOD Calculations \\
\hline Sb & June 2018 & No & Yes & No \\
\hline S1 & June 2018 & Yes & Yes & Yes \\
\hline S2 & June 2018 & Yes & Yes & No \\
\hline S3 & June 2018 & Yes & No & Yes \\
\hline S4 & June 2018 & Yes & No & No \\
\hline W1 & January 2018 & Yes & Yes & Yes \\
\hline W2 & January 2018 & Yes & Yes & No \\
\hline
\end{tabular}




\subsection{Simulation Plan}

We performed two simulations for June 2018 with the previous and improved versions of MESSy-JVAL and compared the results with AERONET measurements, to investigate the effects of the modifications of the photolysis module. In addition, we carried out an additional set of six simulations with the improved version of MESSy-JVAL for the months January 2018 and June 2018. These simulations included different configurations for AOD calculations and interactive weather feedback in the GEM-MACH model, and were used to evaluate the effects of AOD calculations and the online aerosol feedback on the photolysis rates over the entire North American domain and over specific industrial and urban areas. A list of all the simulations is summarized in Table 3. It should be noted that the spatial and temporal resolutions are the same (as described in section 2.4) for all the simulations.

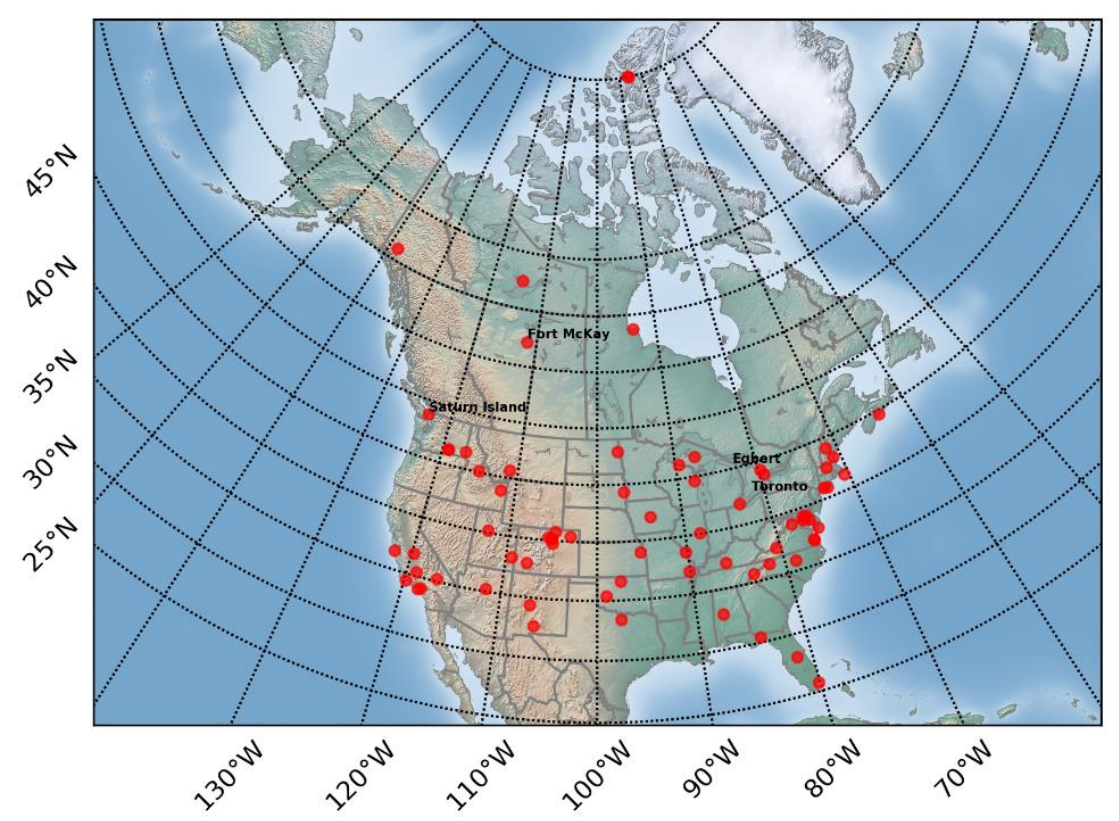

Figure 4: North American AERO NET Sites. AOD data from these stations are used in this study.

\section{Results andDiscussion}

\subsection{Comparis on of base and improved MESSy-JVAL}

In this section, the results of two simulations with the GEM-MACH model for the month of June, 2018 is compared to AERONET sun photometer measurements of AOD at $500 \mathrm{~nm}$ at four North American sites (shown in Fig. 4): simulation Sb with the previous version on MESSy-JVAL (base) and simu lation S1 with the improved photoly sis module (see Table 3). The simulated GEM-MACH AOD output was compared with AERONET sun photometer measurements of AOD at $580 \mathrm{~nm}$ for all North American sites in Fig. 4. As mentioned in section 2.5, we used (440nm - $675 \mathrm{~nm}$ ) AngstromExponent to obtain the 
AERONET AOD at $580 \mathrm{~nm}$. The statistical analy sis of the output from the two GEM-MACH simulations (base and improved) and AERONET AOD at $580 \mathrm{~nm}$ for June 2018 at four Canadian sites, Egbert, Fort McKay, Saturna Is land and Toronto, are shown in Fig. 5. As shown in these plots, the normalized mean bias $\left(N M B=\frac{\sum_{1}^{n}(M-O)}{\sum_{1}^{n}(O)} \times 100\right)$, which represents the mean paired differences between the model and measurements normalized by the mean measurements, is ranging within $\pm 13 \%$ for the improved version and 0\%-150\% for the base version. The NMB calculations from the improved version show an overprediction of AOD in Saturna Island and an under-prediction of AOD in Toronto, Fort McKay and Egbert, whereas the base version shows a significant over-prediction of AOD for all four sites. The root mean square error (RMSE) is significantly smaller in the improved version, with less variability around the mean as shown in the standard deviation $(\sigma)$ plots. The correlation coefficient plots show better results with theimproved version of MESSy-JVAL for all four sites. We calculated a correlation relation of $\mathrm{R}=0.17$ for the base run and $\mathrm{R}=0.37$ for the improved version for all North American AERONET sites.

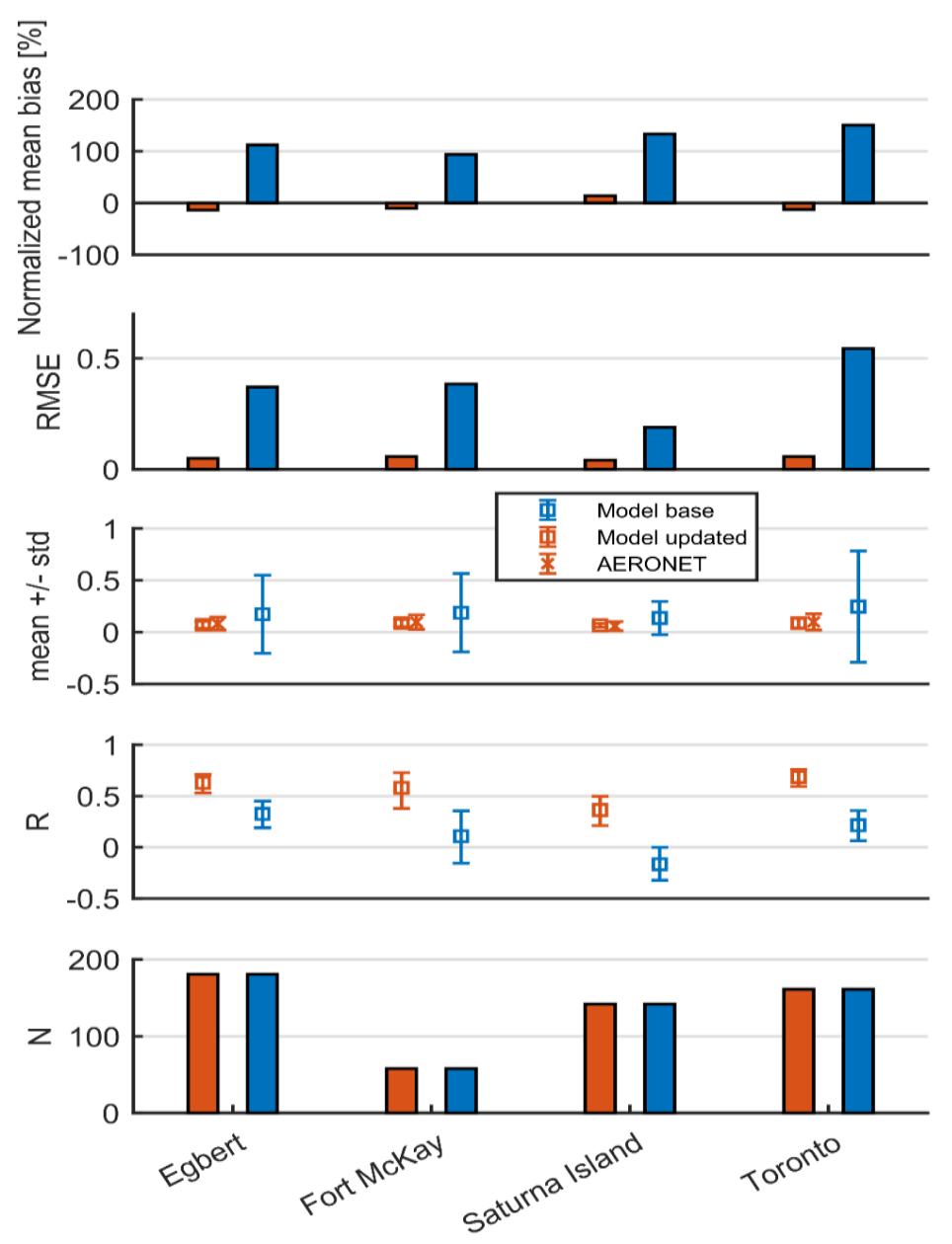

470 Figure 5: Statistical scores of GEM-MACH AOD with the previous (base) and the improved version of MESSy -JVAL versus AERO NET AOD at $580 \mathrm{~nm}$, on June 2018 at four Can adian AERO NET sites, Egbert $\left(44.23^{\circ} \mathrm{N},-79.78^{\circ} \mathrm{W}\right)$, Fort $\mathrm{McKay}^{\circ}\left(57.18^{\circ} \mathrm{N}\right.$, $\left.-111.64^{\circ} \mathrm{W}\right)$, Saturna Island $\left(48.78^{\circ} \mathrm{N},-123.13^{\circ} \mathrm{W}\right)$ and Toron to $\left(43.79^{\circ} \mathrm{N},-79.47^{\circ} \mathrm{W}\right)$. 


\subsection{Evaluation of the improved MESSY-JVAL}

In this section we evaluate the GEM-MACH output with the improved photoly sis module again st the observations and assess the effects of (1) AOD calculations (versus an assumed aerosol optical depth of zero) and (2) interactive aerosol feed back with the GEM model, on the resulting calculated photoly sis rates (see Table 3).

\subsubsection{Comparison with observations}

As described in section 2.6, we performed sixsimulations for the months of January and June 2018, using GEM-MACH model with the updated lookup table and photolysis module. We compared the simulated GEM-MACH AOD with AERONET sun photometer meas urements of AOD at 580nm (converted from AOD at $500 \mathrm{~nm}$ using (440nm- $675 \mathrm{~nm}$ ) Angs tromExponent) for the entire simulation period (January and June 2018) and for all North American sites in Fig. 4.
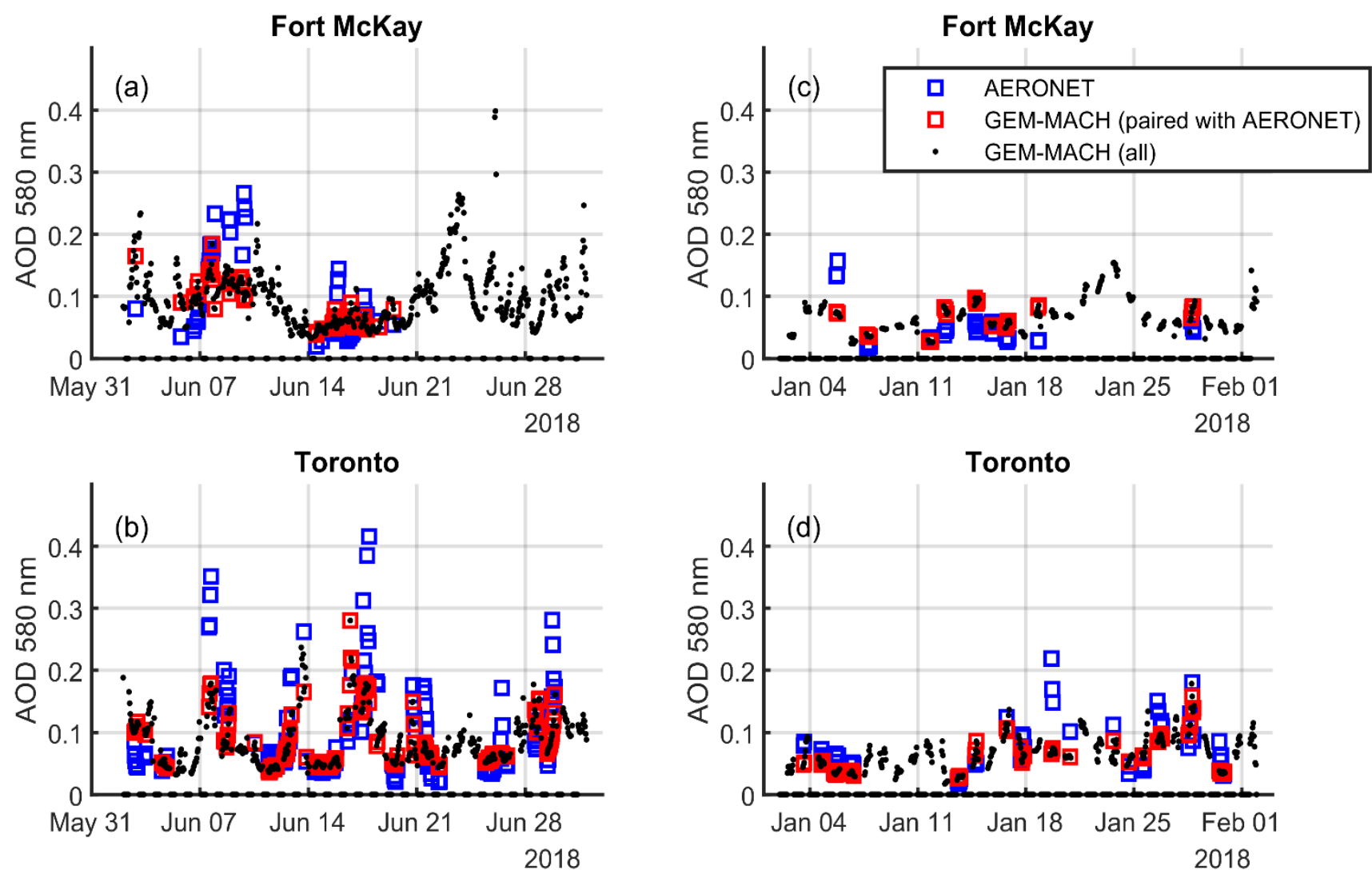

Figure 6: Time series of hourly AERONET and GEM-MACH AOD at $580 \mathrm{~nm}$ at Fort McKay $\left(57.18^{\circ} \mathbf{~ N , ~ - 1 1 1 . 6 4}{ }^{\circ}\right.$ W) and Toronto $\left(43.79^{\circ} \mathrm{N},-79.47^{\circ} \mathrm{W}\right)$ AERO NET station s. Left panel: June 2018, right panel: January 2018. The zero simulated values of AOD (black dots on the $x$-axis) represent no calculation of molecular dissociation by sunlight in the model during nighttime hours. 
Figure 6illustrates the time series of AERONET and GEM-MACH hourly AOD out put at $580 \mathrm{~nm}$ for Fort McKay and Toronto AERONET sites. The output from simulations S1 (with AOD calculations and online aerosol feedbacks, June 2018) and W1 (with AOD calculations and online aerosol feedbacks, January 2018) were used to plot these time series.
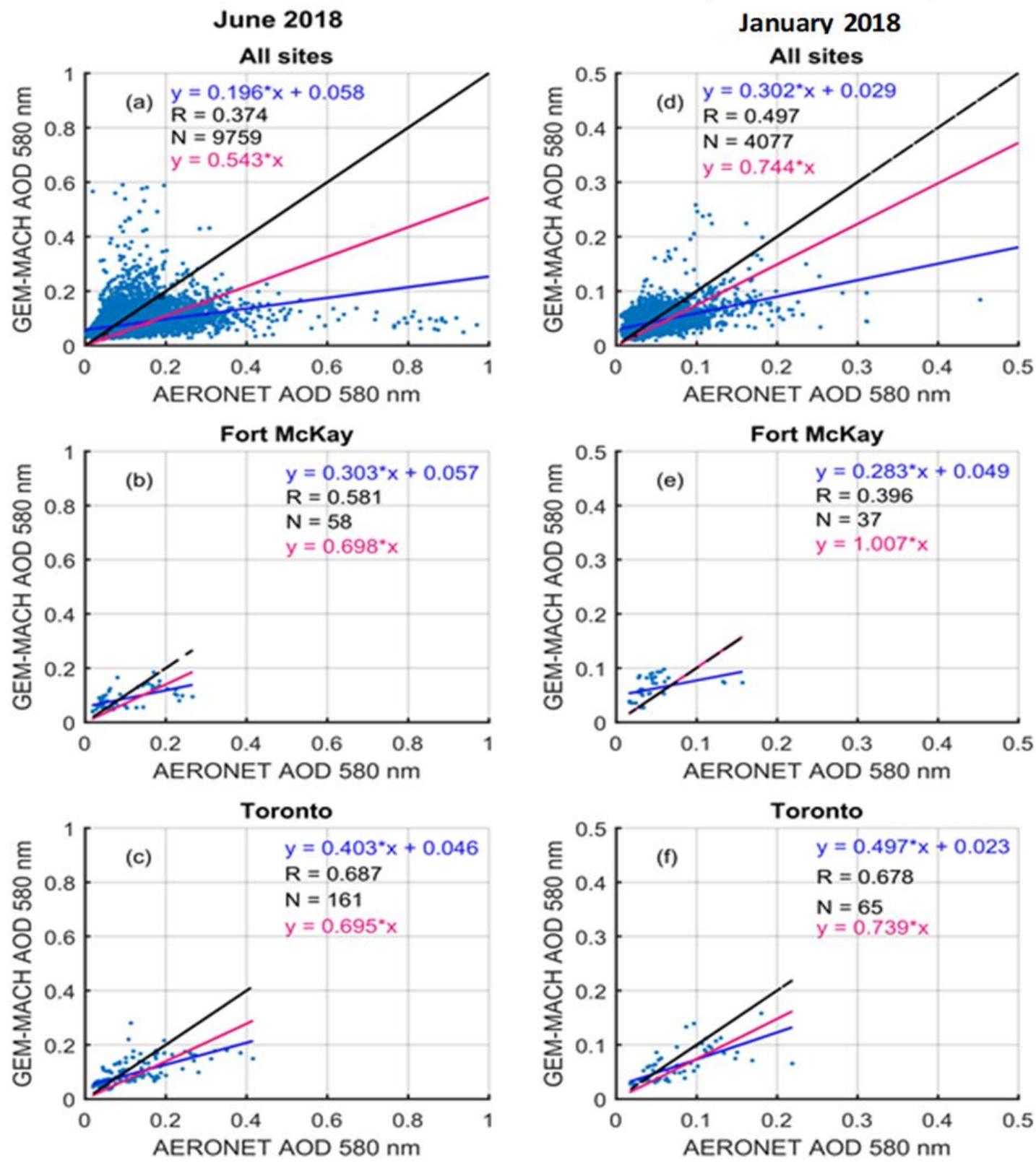

Figure 7: Scatter plots of AERONET AOD vs. GEM-MACH AOD at $580 \mathrm{~nm}$ for all North American sites, Fort McKay (57.18 ${ }^{\circ}$ N, $\left.111.64^{\circ} \mathrm{W}\right)$ and Toron to $\left(43.79^{\circ} \mathrm{N},-79.47^{\circ} \mathrm{W}\right)$ AERO NET stations. Correlation coefficient $(\mathrm{R})$ is calculated for the line with dynamic intercept (blue line). Left panel: June 2018, right panel: January 2018. The blue line represents the linear fit and the red line is the zero-intercept linear fit. The 1:1 line is shown in black. 
As illus trated in Fig. 6, the sample size for Toron to is larger than Fort McKay for both seasons. During the sampling period in summer of 2018, there was an instrument malfunction at Fort McKay fromJune 19 to August 20, which led to having a smaller number of data points at this site compared to Toronto. As shown in these time series, the maximum value of the modeled AOD was underestimated compared to AERONET data for both sites and both simulation periods. For example, the maximum AERONET AOD for the month of June in Fort McKay and Toronto were measured $\sim 0.27$ and $\sim 0.42$ res pectively, whereas the simulated GEM-MACH AOD were $\sim 0.19$ and $\sim 0.29$ for those sites.
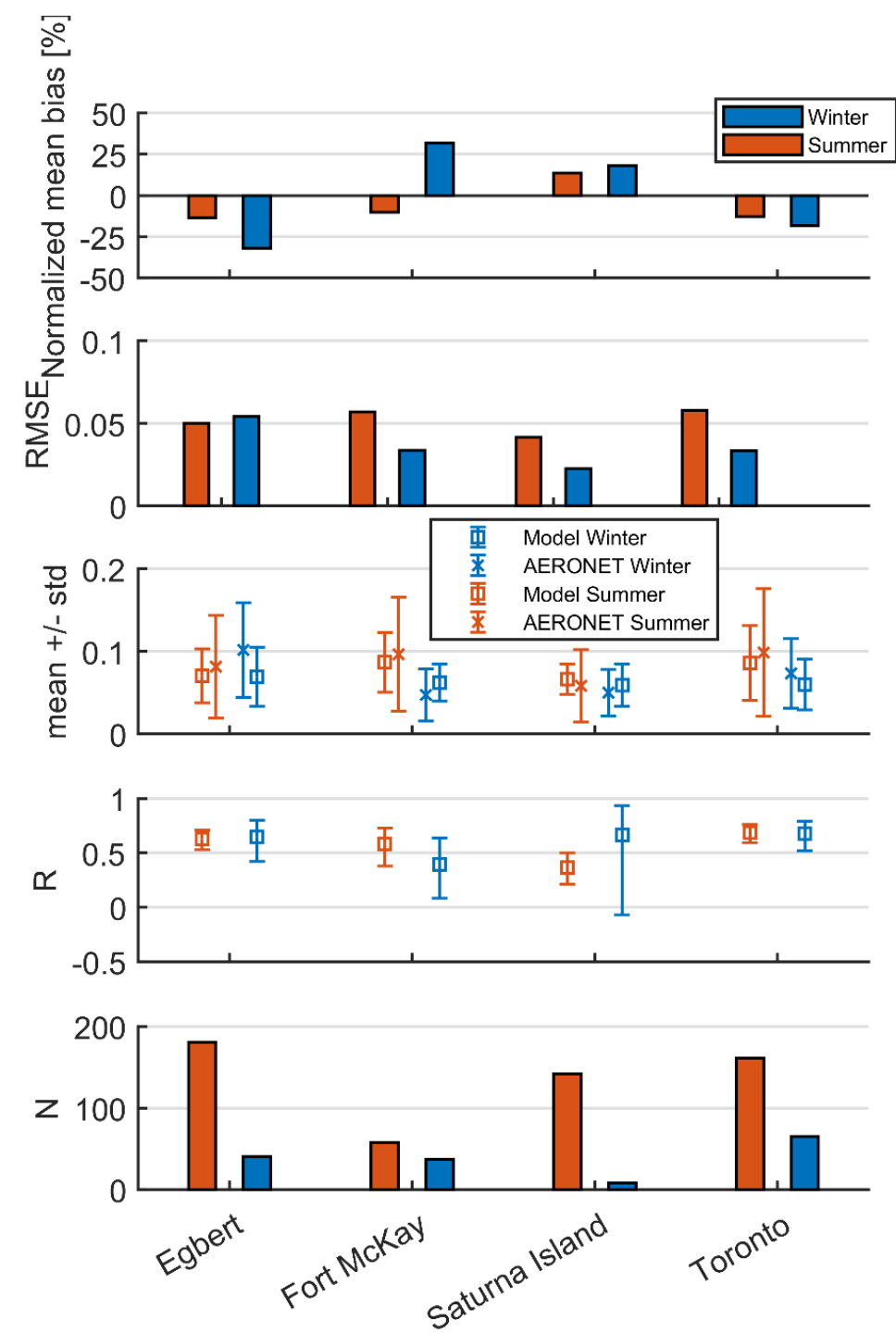

Figure 8: Statistical analysis of GEM-MACH AOD versus AERO NET AOD at $580 \mathrm{~nm}$, on January and June 2018 at four Canadian AERONET sites, Egbert $\left(44.23^{\circ} \mathrm{N},-\mathbf{- 7 9 . 7 8}^{\circ} \mathrm{W}\right)$, Fort McKay $\left(57.18^{\circ} \mathrm{N},-\mathbf{1 1 1 . 6 4}^{\circ} \mathrm{W}\right)$, Saturna Island $\left(48.78^{\circ} \mathrm{N}, \mathbf{- 1 2 3 . 1 3}^{\circ} \mathrm{W}\right)$ and Toron to $\left(43.79^{\circ} \mathrm{N},-79.47^{\circ} \mathrm{W}\right)$. 
Scatter plots of AERONET AOD vs. GEM-MACH AOD (from simulations S1 and W 1) at $580 \mathrm{~nm}$ for all North American sites, Fort McKay and Toronto AERONET stations are shown in Fig. 7. The total number of measurements is N=9759 for summer and $\mathrm{N}=4077$ for winter for all AERONET sites. As shown in the top row of Fig. 7, the correlation coefficient (R) between the model and measurements is 0.37 for summer and 0.49 for winter. There is a higher correlation for Toronto compared to Fort McKay for both seasons.

The statis tical scores of GEM-MACH vs. AERONET AOD at $580 \mathrm{~nm}$ for January and June 2018 at four Canadian AERONET sites, Egbert, Fort McKay, Saturna Is land and Toronto are shown in Fig. 8. It should be noted that the number of coincident data points is considerably smaller in winter. As shown in these plots, the normalized mean bias (NMB) is ranging within $\pm 13 \%$ in summer and $\pm 32 \%$ in winter. The NMB calculations show an over-prediction of AOD in Saturna Island for both seasons and Fort McKay in winter, whereas there is an under-prediction of AOD in Toronto and Egbert for both seasons. The root mean square error (RMSE) plots show a better fit of the model AOD to measurements in winter season. The standard deviation $(\sigma)$ plots show more variability around the mean in AERONET measurements for both seasons compared to model values.
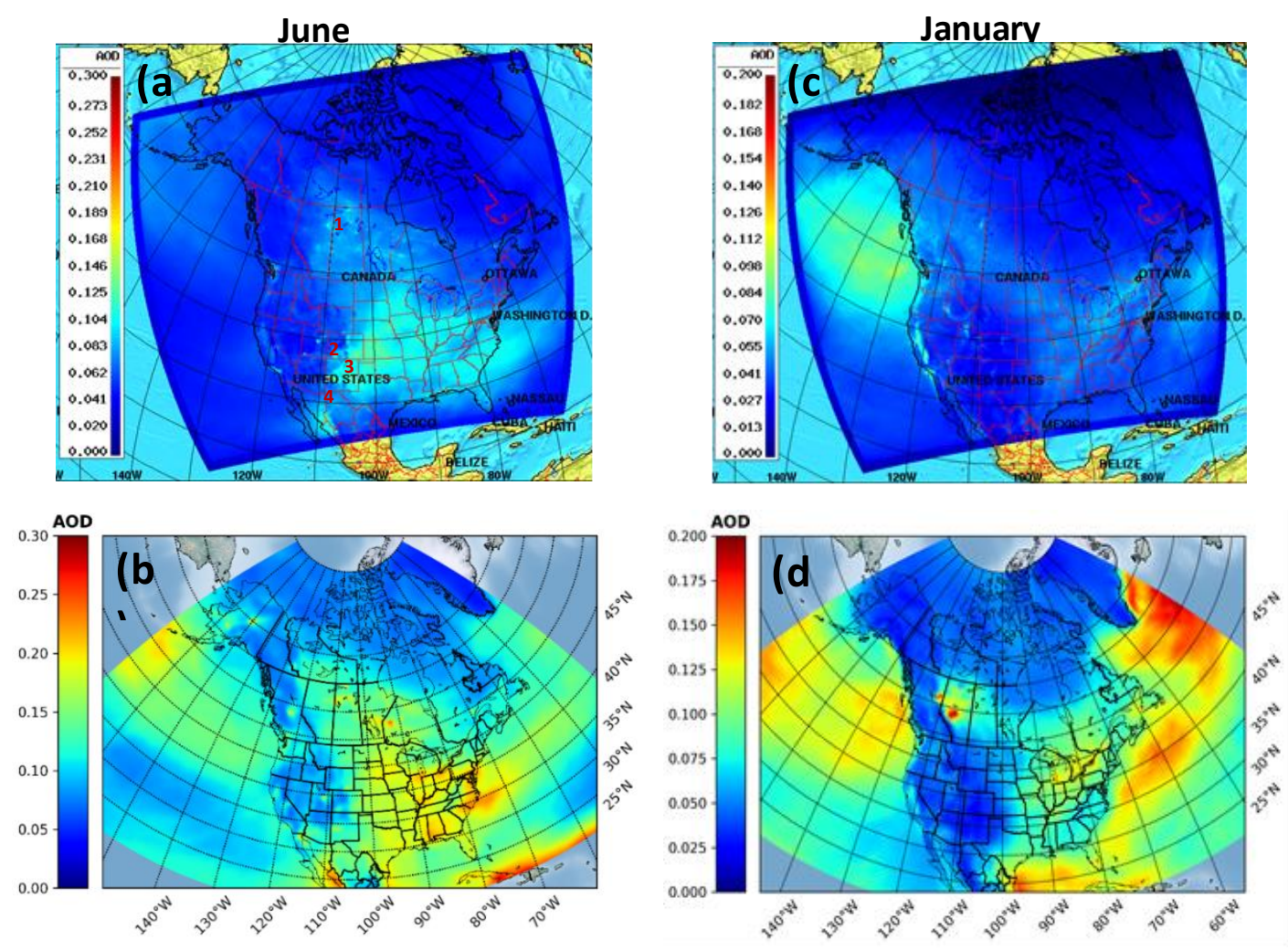

Figure 9: Monthly average daytime AOD at $580 \mathrm{~nm}$ from GEM-MACH and MERRA-2 model. Left column, June 2018 a) GEMMACH AOD b) MERRA-2 AOD. Right column, January 2018 c) GEM-MACH AOD d) MERRA-2 AOD. Four major forest fire events in June 2018shown in GEM-MACH output (a): (1) Lac La Loche forest fire, (2)416 fire, (3) Ute Park fire (4) Gila National Forest fire. 
Figure 9 shows the monthly averaged daytime AOD at $580 \mathrm{~nm}$ from GEM-MACH simulations and MERRA-2 re-analysis. The total monthly averaged aerosol Angstromparameter $(470-870 \mathrm{~nm})$ and equation 20 were used to calculate MERRA-2 AOD at $580 \mathrm{~nm}$ (with different scales in summer and winter plots). As shown in the summer plots, GEM-MACH captured four major forest fire events during the month of June 2018: Lac La Loche forest fire in Saskatchewan (June 25, 2018), La Plata County's 416 fire in Colorado (June 1,2018), Ute Park fire in New Mexico (June 1,2018) and Gila NationalForest fire in New Mexico (May-July, 2018). Higher values of AOD over the Pacific Ocean over the month of January 2018 can be seen on both GEM-MACH and MERRA-2 plots. Over the common domain, there is an underestimation of monthly average AOD in the GEM-MACH model compared to MERRA-2 for both seasons.

\subsection{Sensitivity test to AOD calculations and aerosol feedback}

In this section we evaluate the impacts of AOD calculations on photolysis rates calculations with the improved photolysis module in the GEM-MACH model. We also assess the effects of the model-generated aerosols on the radiative transfer and cloud formation processes in GEM-MACH, through the comparis ons of the optical properties of aerosols in the 'feedback' mode (Makar et al., 2015a, b) vs 'no-feedback' mode, in which the feedback mechanisms (interactions between meteorology and chemistry) have been dis abled and the model uses climatological parameterizations for the aerosol dire ct and indirect effects.

Figure 10 shows the monthly average percentage difference in photolysis rate coefficients $\left(\mathrm{J}\left(\mathrm{O}^{1} \mathrm{D}\right)\right.$ and $\left.\mathrm{J}\left(\mathrm{NO}_{2}\right)\right)$ with and without AOD calculations in the photolysis module in GEM-MACH model. The top two panels are the simulation outputs with online aeros ol feedback between weather and air-quality in the model. We used the output fromsimulations S1 and S2 to calculate the percentage difference in photolysis rates in Fig. 10(a) and (b), and the output from simulations W1 and W2 in Fig. 10(c) and (d). The percentage difference in summer (top row) and winter (second row) ranges from -10\% to $10 \%$ and the spatial distribution of the changes does not vary significantly between $\mathrm{J}\left(\mathrm{O}^{1} \mathrm{D}\right)$ and $\mathrm{J}\left(\mathrm{NO}_{2}\right)$. The bottom row of Fig. 10 is the monthly average percentage difference in $\mathrm{J}\left(\mathrm{O}^{1} \mathrm{D}\right)$ and $\mathrm{J}\left(\mathrm{NO}_{2}\right)$ at the lowest model level (June 2018) with and without AOD calculations. The output from simulations S3 and S4 were used in Fig. 10(e) and (f), meaning there is no online aerosol feedback in these simulations. As shown in Fig. 10(e) and (f), there is not a significantchange in monthly-averaged photolysis rates $(-0.1 \%$ to $0.1 \%$ ) with no online aerosol feedback on weather in the model (Fig. 10 (e) and (f)). The increase in the photolysis rates differences, and the less org anized structure of these changes over the domain in simulations with the online aerosol feedbacks, is due to the presence of the direct and indirect effects from meteorological changes such as changes in cloud patterns, and amplified chemis try perturbations due to weather feedback.

Figure 11 is the monthly average percentage difference in $\mathrm{AOD}, \mathrm{J}\left(\mathrm{O}^{1} \mathrm{D}\right)$ and $\mathrm{J}\left(\mathrm{NO}_{2}\right)$ in June 2018 and at the lowest model level with and without interactive aerosol feedback on weather in the model(simulations S1 and S3). This figure shows the effects of the interactive online aerosol feed back on the output of the photolysis module. Note that in both simulations we used AOD calculations in the photoly sis module. As shown in this figure, AOD changes from -30\% to $30 \%$ and J-values from- $40 \%$ to 
https://doi.org/10.5194/gmd-2021-172

Preprint. Discussion started: 8 July 2021

(c) Author(s) 2021. CC BY 4.0 License.

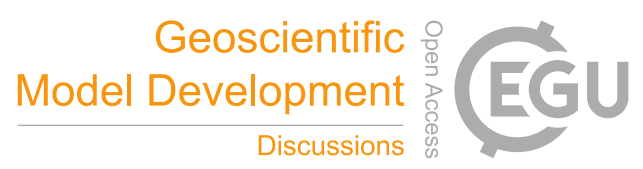

40\% with and without the GEM-MACH predicted aerosol concentrations in optical properties and photoly sis rates calculations.

The increase of AOD and the resulting decrease of J-values over the continent, might be due to the increase in the cloud droplet density, and/or in-cloud formation of aerosols in the simulations with interactive aerosol feedback in the model. The results from Fig. 10 and Fig. 11 suggest that the impacts of aerosol feedbacks as parameterized in the model are considerably greater than the impacts of the AOD calculations in the model.

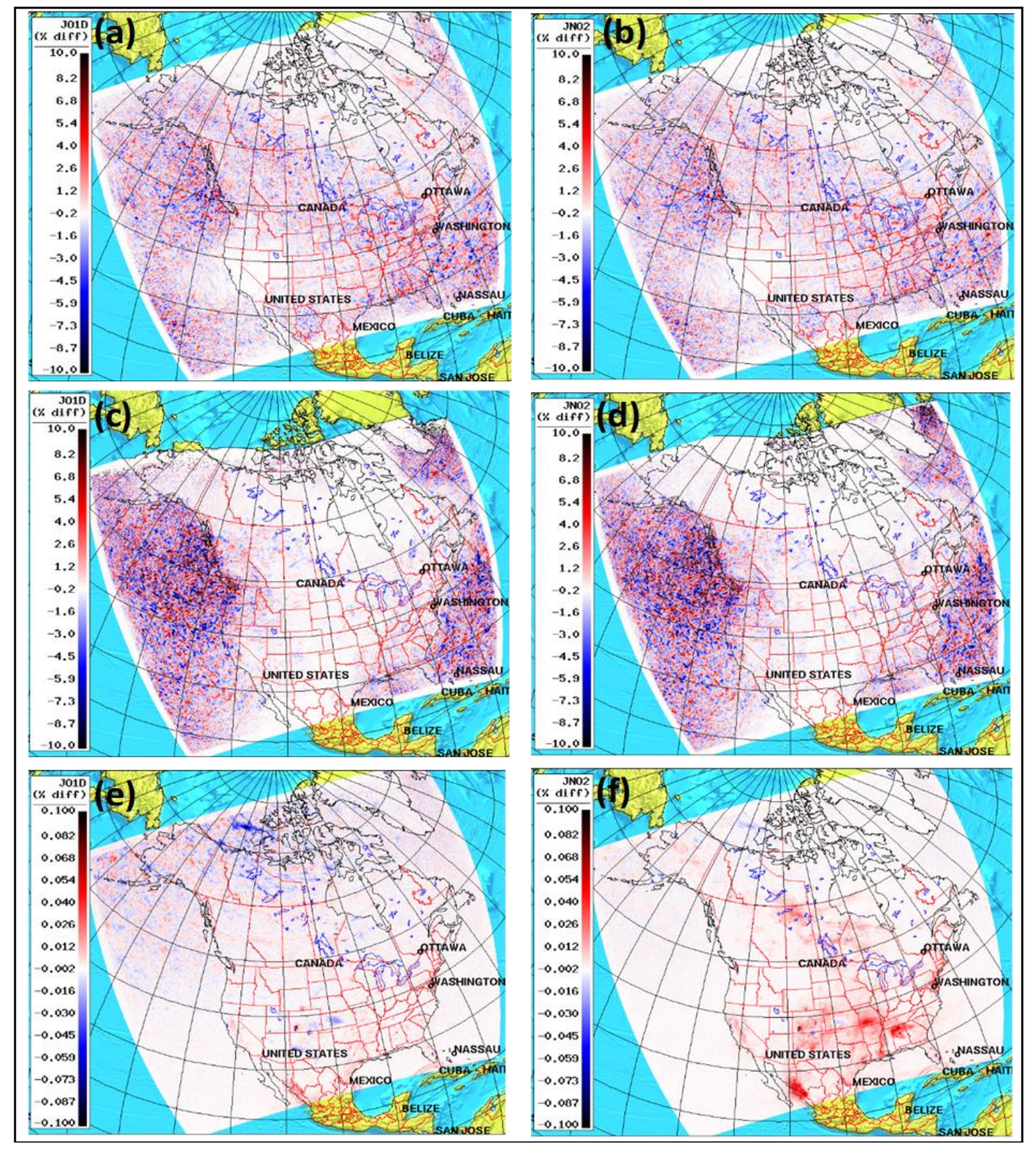

Figure 10: Percentage difference $\left(\frac{J_{a o d}-J_{n o-a o d}}{\left(J_{a o d}+J_{n o-a o d}\right) / 2} \times 100\right)$ in daytime monthly-ave raged photolysis rates $\left(\mathrm{J}^{\circ}\left(\mathrm{O}^{1} \mathrm{D}\right)\right.$ and $\left.\mathrm{J}(\mathrm{NO})\right)$ at the lowest model level, with and with out AOD calculations. a, b) June 2018 with online interactive aerosol f e edback. c, d) January 2018 with online in teractive ae rosol feedback.e, f) June 2018 with ou tonline in teractive aerosol feedback. 

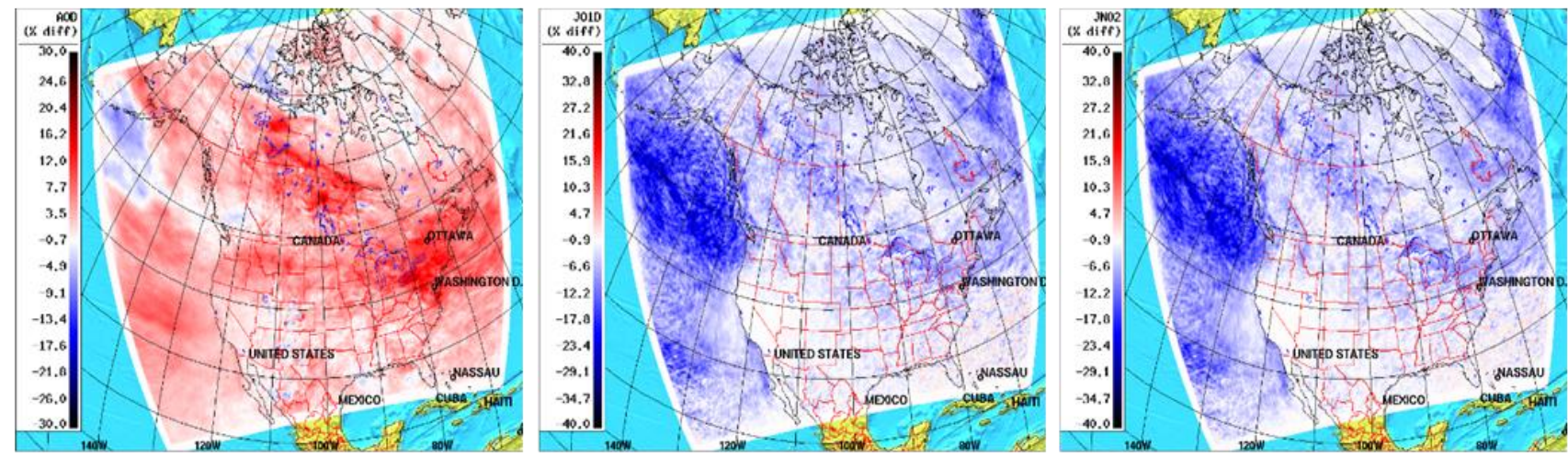

Figure 11: : From left to right: Percentage difference in daytime monthly average (June 2018) AOD, JO ${ }^{1} \mathrm{D}$ and $\mathrm{JNO}_{2}$ at the lowest model level, with and without online aerosol feedbacks.

His tograms and the statistical scores of hourly percentage difference in $\mathrm{J}\left(\mathrm{O}^{1} \mathrm{D}\right)$ at Fort McKay and Toronto AERONET stations at the lowest model level, with and without AOD calculations in June 2018 are shown in Fig. 12 and Table 4. With the interactive aerosol feedbacks in the model (simulations S1 and S2), the standard deviation for Fort McKay and Toronto stations are 29.3 and 28.7 respectively, showing the average of approximately $29 \%$ change in $\mathrm{J}\left(\mathrm{O}^{1} \mathrm{D}\right)$ around the mean, with more frequent changes within $\pm 10 \%$ for both stations. The $95^{\text {th }}$ percentile shows that $95 \%$ of the data points (percentage difference in $\mathrm{J}\left(\mathrm{O}^{1} \mathrm{D}\right)$ values) are below $36.2 \%$ for Fort McKay and $\sim 2 \%$ for Toronto (Fig. 12(a), (b)) . In the cases without the online aerosol feedback in the model (simulations S3 and S4), the standard deviation for both stations is considerably smaller ( 0.55 for Toronto and 0.21 for Fort McKay) and the values of percentage difference in $\mathrm{J}\left(\mathrm{O}^{1} \mathrm{D}\right)$ are more clustered around the mean (Fig. 12(c), (d)). The more-organized changes in photolysis rates in the no-feedback case, is due to including only the direct effect of photolysis on aerosols, whereas, the effect of clouds and in-cloud formation of aerosols in the feedback case leads to more variability in the photolysis rate changes between simulations S1 and S2. 
Toronto
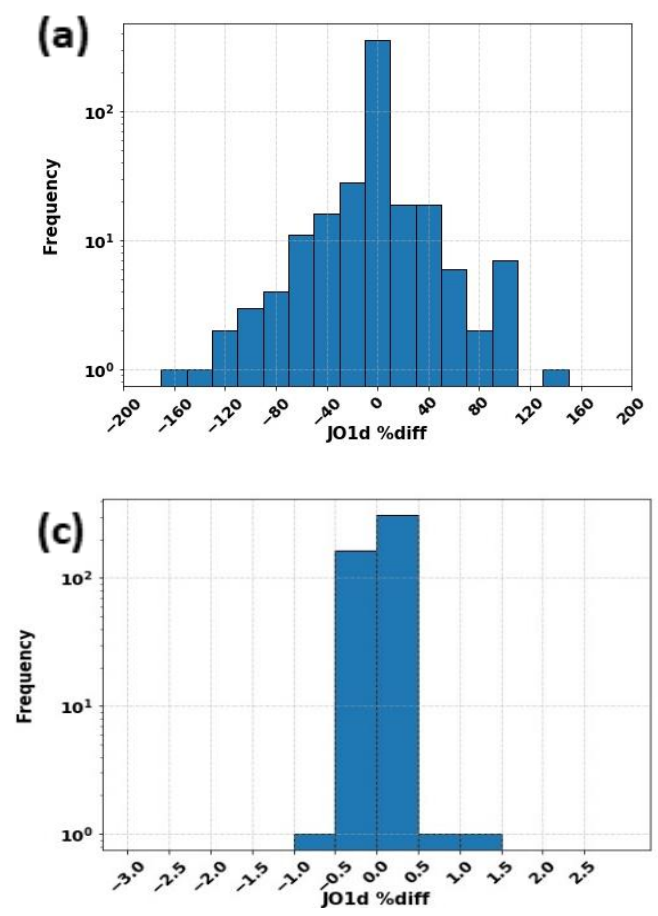

Fort McKay
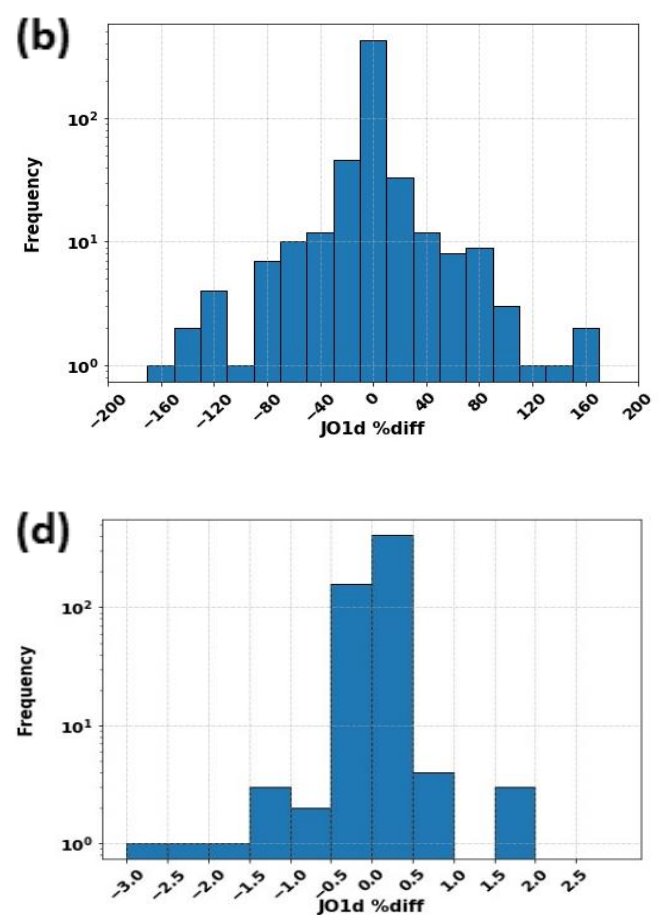

Figure 12: : Histograms of percentage difference of hourly $\mathrm{JO}^{1} \mathrm{D}$ output for June 2018 at Toronto and Fort McKay AERO NET stations at the lowest model level, with and without AOD calculations. (a), (b) are with aerosol feedbacks and (c), (d) are without ae rosol feedbacks. Nighttime data $\left(\mathrm{JO}^{1} \mathrm{D}=0\right)$ was omitted from the analysis.

\begin{tabular}{|l|l|l|l|l|}
\hline \multicolumn{5}{|c|}{ Percentage Difference in J(O'D) } \\
\hline & \multicolumn{2}{|c|}{ With Aerosol Feedbacks } & \multicolumn{2}{c|}{ Without Aeros ol Feedbacks } \\
\hline & Fort McKay & \multicolumn{1}{|c|}{ Toronto } & \multicolumn{1}{|c|}{ Fort McKay } & \multicolumn{1}{c|}{ Toronto } \\
\hline $\begin{array}{l}\text { Standard } \\
\text { Deviation }\end{array}$ & 29.25 & 28.7 & 0.213 & 0.547 \\
\hline Mean & -0.96 & -0.65 & -0.006 & 0.035 \\
\hline Median & 0.0 & 0.0 & 0.0 & 0.0 \\
\hline 5 Percentile & -38.87 & -44.63 & -0.103 & -0.062 \\
\hline 25 Percentile & -1.45 & -0.31 & -0.003 & -0.012 \\
\hline 75 Percentile & 0.60 & 0.09 & 0.007 & 0.016 \\
\hline 95 Percentile & 36.17 & 41.94 & 0.214 & 0.134 \\
\hline
\end{tabular}

Table 4: Statistical scores of percentage difference of $\mathbf{J}\left(\mathrm{O}^{1} \mathrm{D}\right)$, with and without AOD calculations $\left(\frac{J_{a o d}-J_{n o-a o d}}{\left(J_{a o d}+J_{n o-a o d}\right) / 2} \times 100\right)$ at Fort McKay and Toronto AERO NET stations. From one-month GEM-MACH J(O $\left.{ }^{1} \mathrm{D}\right)$ output at the lowest model level on June 2018. 


\subsection{Case study: Lac La Loche forest fire}

In order to evaluate the impacts of the modifications of the photolysis calculations on air qua lity under high pollutant flux emissions conditions, we study a forest fire case in the Lac La Loche area in the northwestern corner of the province of Saskatchewan of Canada on June 25, 2018 (Fig. 13).

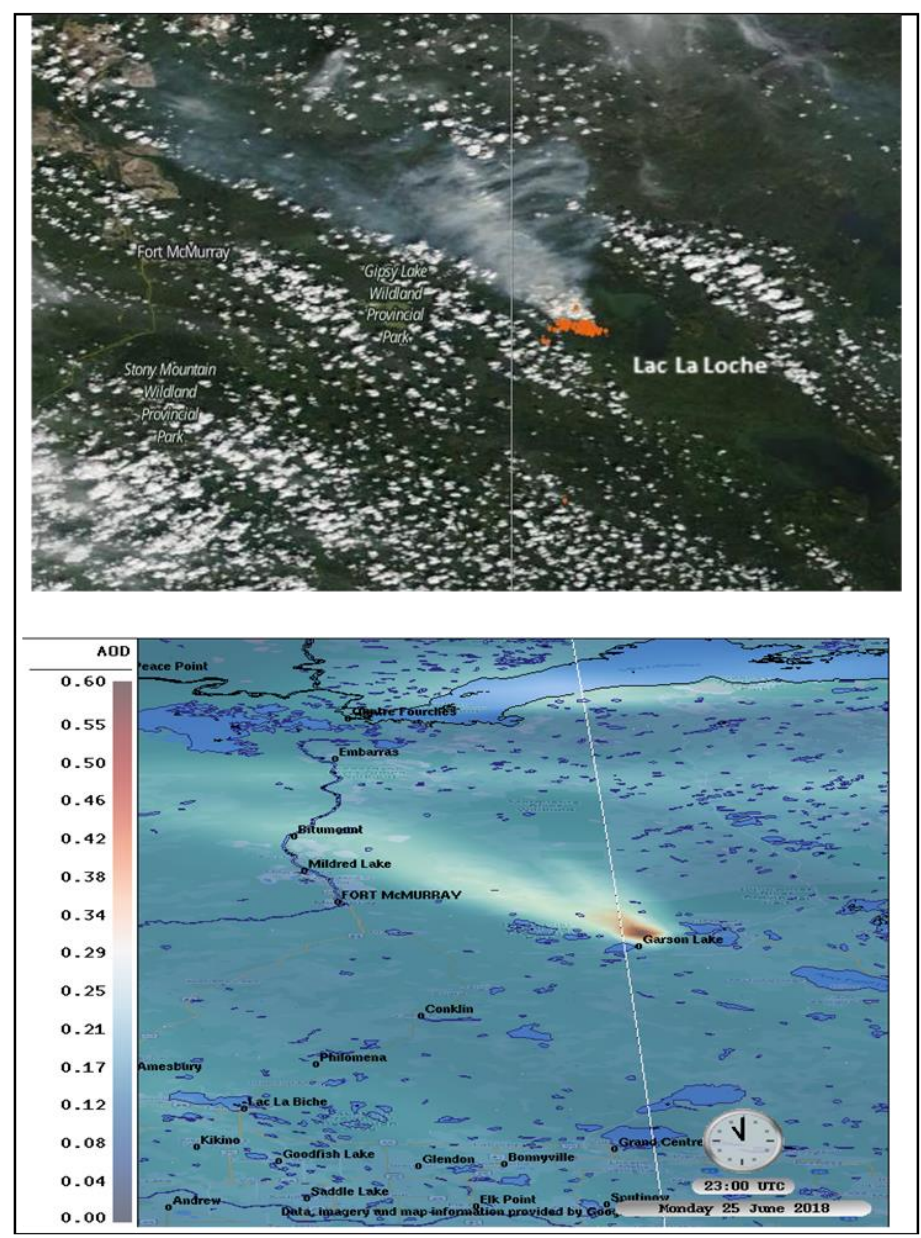

Figure 13: : Lac La Loche forest fire on June 25, 2018. Top : Image from: https://worldview.earthdata.nasa.gov. Overlay layer: MO DIS - Terra thermal anomalies (day and night), over MODIS Terra true color corrected reflectance. Bottom: GEM-MACH AOD at $580 \mathrm{~nm}$ at 23:00 UTC.

Figure 14(a) shows the daily aerosol optical depth at $580 \mathrm{~nm}$ from the Moderate Resolution Imaging Spectroradiometer

(MODIS-Terra Level 3 Atmos phere Gridded Product). Daily aerosoloptical depth at 550 nm and Angstromexponent for the aerosols over land based on 470 and $660 \mathrm{~nm}$ optical depths are available through NASA Earth Data Giovanni (https://giovanni.gsfc.nasa.gov/giovanni/). Fig. 14(b) is MERRA-2 total aerosol extinction (AOT) at 550 nm at 23:00 UTC and Fig. 14(c) is GEM-MACH AOD at $580 \mathrm{~nm}$ over La Loche area at 23:00 UTC on June 25, 2018. MERRA-2 (Fig. 14(b)) 
shows two areas of maxima; one is directly over the forest fire plume, similar to the hotspot on GEM-MACHplot (Fig. 14(c)) and the weaker hotspot over the s ame area in MODIS-Terra plot (Fig. 14(a)). The second maximum value in MERRA-2 (Fig. 14(b)) is located downwind of the forest fire plume over the Athabasca Oil Sands region of northeastern Alberta, which is not detected in MODIS-Terra plot (Fig. 14(a)), and is more intensified, compared to GEM-MACH values. One possible reason that GEM-MACH did not show high values of AOD over the second hotspot could be the coarse horizontal res olution of the model for these simulations $(10 \mathrm{~km} \times 10 \mathrm{~km})$. Another explanation could be potential deficiencies in Oil Sands emis sions or aerosol processes in this simulation.
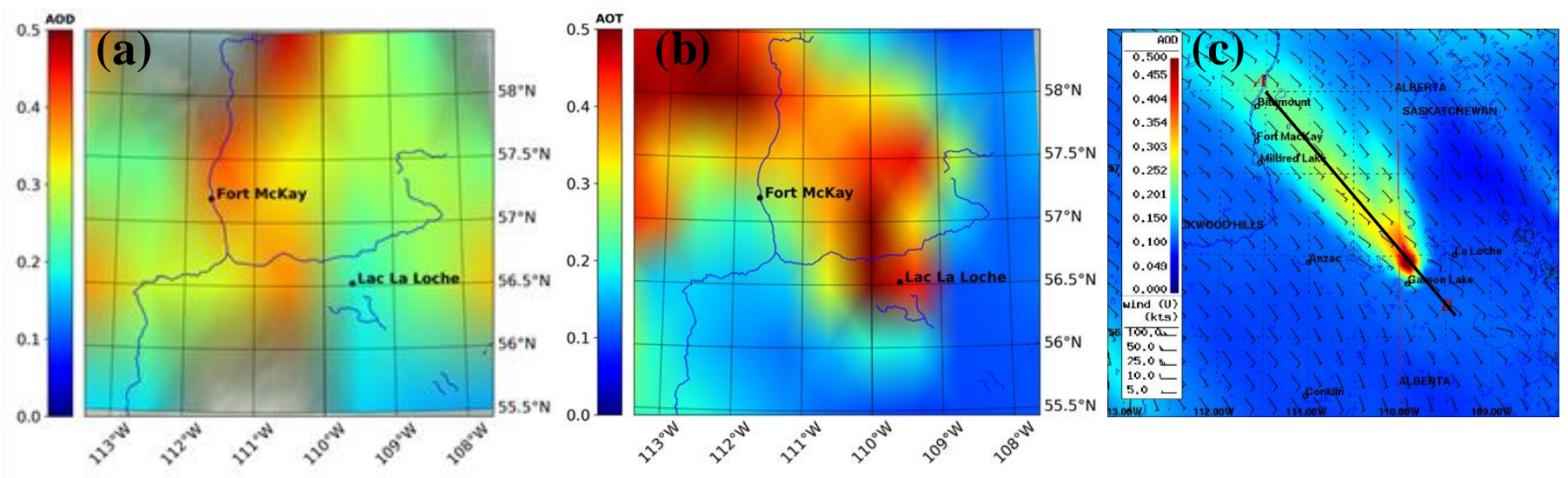

Figure 14: Lac La Loche forest fire, June 25,2018 (a): MO DIS-Terra daily AOD at 580 nm, (b): MERRA-2 total aerosol extinction (AOT) at $550 \mathrm{~nm}$ at 23:00 UTC and (c): GEM-MACH AOD at $580 \mathrm{~nm}$ at 23:00 UTC. The cross sections in Fig. 15, Fig. 16 and Fig. 17 are plotted along the black line in $(c)$.

Figure 15 shows the aerosol concentrations and photoly sis rates cross sections over the black solid line in Fig. 15(c). As shown in Fig. 15(a), $\mathrm{O}_{3}$ is impacted by titration below the PBL(Planetary Boundary Layer), and there is a low concentration of ozone right above the fire plume. Higher concentrations of $\mathrm{O}_{3}$ can be seen downwind below the PBL. As the fire plume continues to dilute with dis tance down wind, the $\mathrm{NO}_{x}$ concentration in the boundary layer (not shown) decreases and eventually reaches an optimal concentration range for efficient ozone production. This is illustrated in Fig. 15(a) as ozone increases to near $80 \mathrm{ppbv}$ about $170 \mathrm{~km}$ down wind from the fire. Figure 15(b) shows the depletion of hydroxyl radical $(\mathrm{OH})$ in the fire plume below the PBL and a maxima above the boundary layer, where there is a high concentration of $\mathrm{O}_{3}$ and low concentration of VOC (Volatile Organic Compound) to deplete $\mathrm{OH}$. The increase in $\mathrm{OH}$ downwind from the fire plume is in response to the $\mathrm{O}_{3}$ increase, reaching a maximum value of $\sim 2.3 \times 10^{-4} \mu \mathrm{g} \mathrm{kg}^{-1}\left(\sim 7.5 \times 10^{6}\right.$ molecules $\left.\mathrm{cm}^{-3}\right)$ in the upper boundary layer $\sim 700-800 \mathrm{hPa}$. The increase in $\mathrm{OH}$ concentration results in delayed production of secondary aerosol components. The $\mathrm{PM}_{2.5}$ predicted in the forest fire plume (Fig. 15(c)) reached a maximum value of $65 \mu \mathrm{g} \mathrm{m}^{-3}$ near the surface and remained above $10 \mu \mathrm{g} \mathrm{m}^{-3}$ up to $800 \mathrm{hPa}$. As shown in Fig. 15(d), the fire plume was predicted to penetrate above the boundary layer height due to the black carbon plume mixing up to $600 \mathrm{hPa}$. The black carbon concentration decay with dis tance illus trates the extent of dilution of directly emitted $\mathrm{PM}_{2.5}$ components as it mixes horizontally. As shown in Fig. 15(e), the concentration of SOA increases downwind from the fire plume. Similarly, the concentration of nitrate(Fig. 15(f)) increases downwind between $900 \mathrm{hPa}$ and theboundary 
layerdue to secondary production and the long-lived nature of nitrate. The attenuation of radiation by the fresh fire plume is illus trated by the decrease in $\mathrm{J}\left(\mathrm{NO}_{2}\right)$ below the PBL from $1.26 \times 10^{-2} \mathrm{~s}^{-1}$ at $\sim 700 \mathrm{hPa}$ to $4.52 \times 10^{-3} \mathrm{~s}^{-1}$ at the surface and $\mathrm{J}\left(\mathrm{O}^{1} \mathrm{D}\right)$ from $1.83 \times 10^{-5} \mathrm{~s}^{-1}$ at $\sim 700 \mathrm{hPa}$ to $5.48 \times 10^{-6} \mathrm{~s}^{-1}$ at the surface(Fig. $15(\mathrm{~g})$ and $(\mathrm{h})$ ). The photolysis rates decrease with distance is due to the attenuation of radiation by the directly emitted fire $\mathrm{PM}_{2.5}$ components.

In order to evaluate the effects of aerosol optical properties in aerosol concentrations and photoly sis rates in Lac La Loche fire event, we calculated the percentage difference in aerosol concentrations and photolysis rates with and without AOD calculations (simulations S1 and S2). Figure 16 shows the percentage difference of aerosol concentrations and photolysis rates cross sections with and without AOD calculations over the Lac La Loche forest fire event on June 25, 2018 (black solid line in Fig. 15(c)). Figure 16(a) shows the reduction of $\mathrm{O}_{3}$ in the fresh fire plume below the PBL due to the decrease in $\mathrm{J}\left(\mathrm{O}^{1} \mathrm{D}\right)$, reaching a difference close to $0.9 \%$ near the surface. The $\mathrm{OH}$ radical concentration difference (Fig. 16(b)) responds to the $\mathrm{O}_{3}$ change and decreases by up to $3 \%$ at the surface due to the AOD feedback on the photolysis rates. This affects the rate of production of secondary aerosol components such as nitrate (Fig. 16(f)) and secondary org anic material(Fig. 16(e)), although there is a small decrease of up to $7 \%$ in nitrate concentration in the fresh plume. There is a reduction in $\mathrm{J}\left(\mathrm{NO}_{2}\right)$ and $\mathrm{J}\left(\mathrm{O}^{1} \mathrm{D}\right)$ (Fig. 16(g) and (h)) in the fire plume below the boundary layer. As shown in Fig. 16(c) and (d), after including AOD calculations in the model, the concentrations of $\mathrm{PM}_{2.5}$ and black carbon decrease by $5 \%$ in the fire plume from the surface to $900 \mathrm{hPa}$ and increase by $5 \%$ above $900 \mathrm{hPa}$ and below the bound ary layer.

Figure 17 is the percentage difference in aerosol concentrations and photolysis rates, with and without AOD calculations and no aerosol feedbacks in the model (simulations S3 and S4). As shown in Fig. 17(c), (d) and (e), without the interactiveaerosol feedbacks in the model, there is an insignificant difference (-0.2\% to $0.2 \%$ ) in $\mathrm{PM}_{2.5}$, black carbon and SOA concentrations compared to the difference in concentrations from simulations S1 and S2 (-50\% to 50\% with aerosol feedbacks). Similarly, there is $-1 \%$ to $1 \%$ difference in $\mathrm{O}_{3}$ concentrations (Fig. 17(a)) from simulations $\mathrm{S} 3$ and $\mathrm{S} 4$. The variability in the production of $\mathrm{OH}$ (Fig. 17(b)) by the photolysis of $\mathrm{O}_{3}$ is more considerable (-5\% to 5\%). The decrease in the $\mathrm{OH}$ concentration with primary-aerosol-component photolysis attenuation results in lower secondary aerosol production downwind, which in tum, slowly counters the primary aerosol attenuation and increases the photolysis rates (maximum of $<1 \%$ ). The increased photolysis difference results in a positive difference between the ozone and $\mathrm{OH}$ concentrations. The predicted $\mathrm{OH}$ increases down wind reaching a maximum of $1 \%$. 

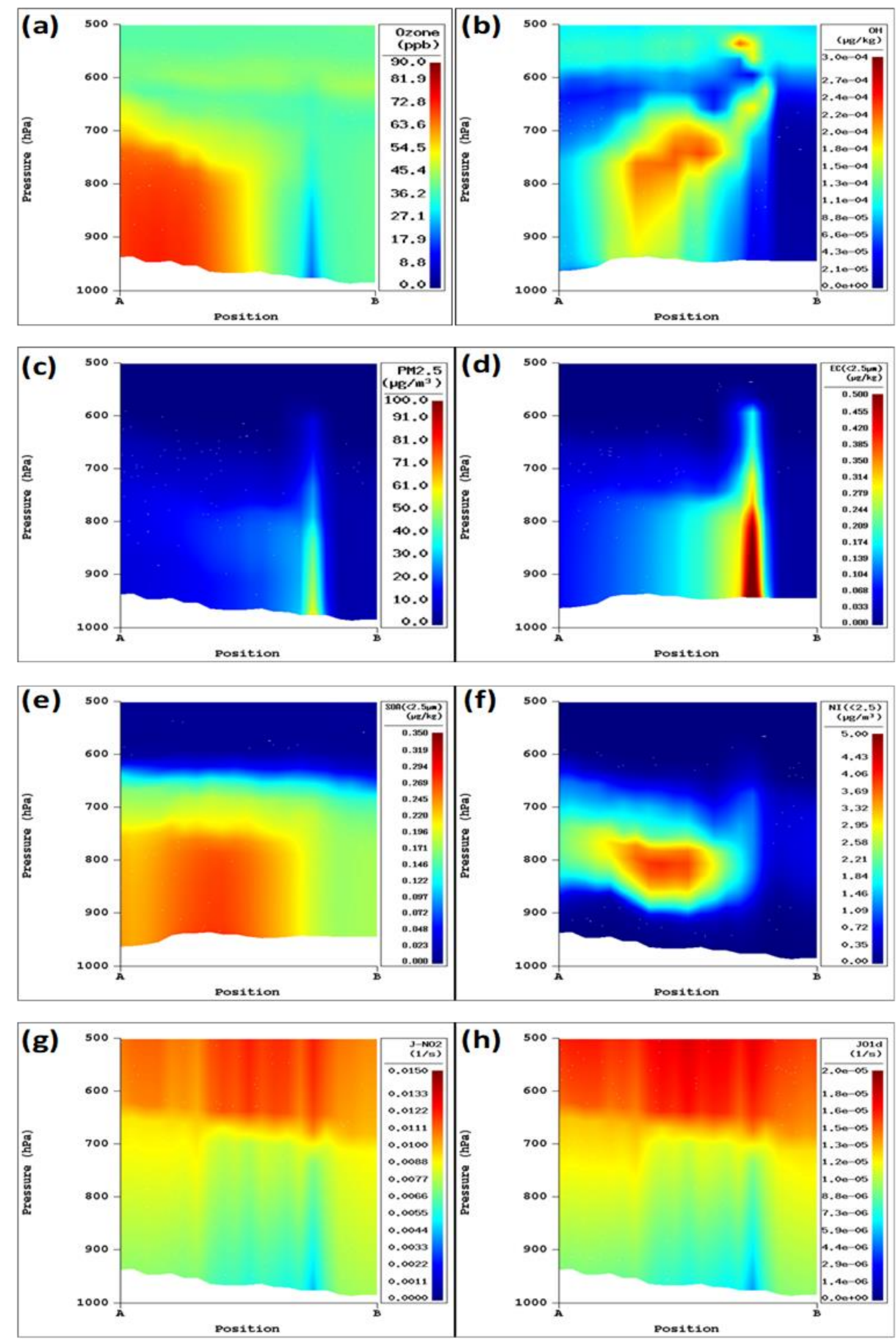

Figure 15: Cross sections of gas and ae rosol concentrations and photolysis rates with aerosol feedbacks over the line shown in Fig.

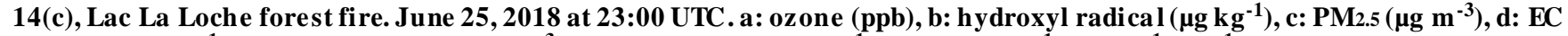
$\left(<2.5 \mu \mathrm{m}, \mu \mathrm{g} \mathrm{kg}^{-1}\right)$, e : nitrate $\left(<2.5 \mu \mathrm{m}, \mu \mathrm{g} \mathrm{m}^{-3}\right)$, f: SO A $\left(<2.5 \mu \mathrm{m}, \mu \mathrm{g} \mathrm{kg}^{-1}\right), \mathrm{g:}$ : J(NO 2$)\left(\mathrm{s}^{-1}\right), \mathrm{h}: \mathrm{J}\left(\mathrm{O}^{1} \mathrm{D}\right)\left(\mathrm{s}^{-1}\right)$. 

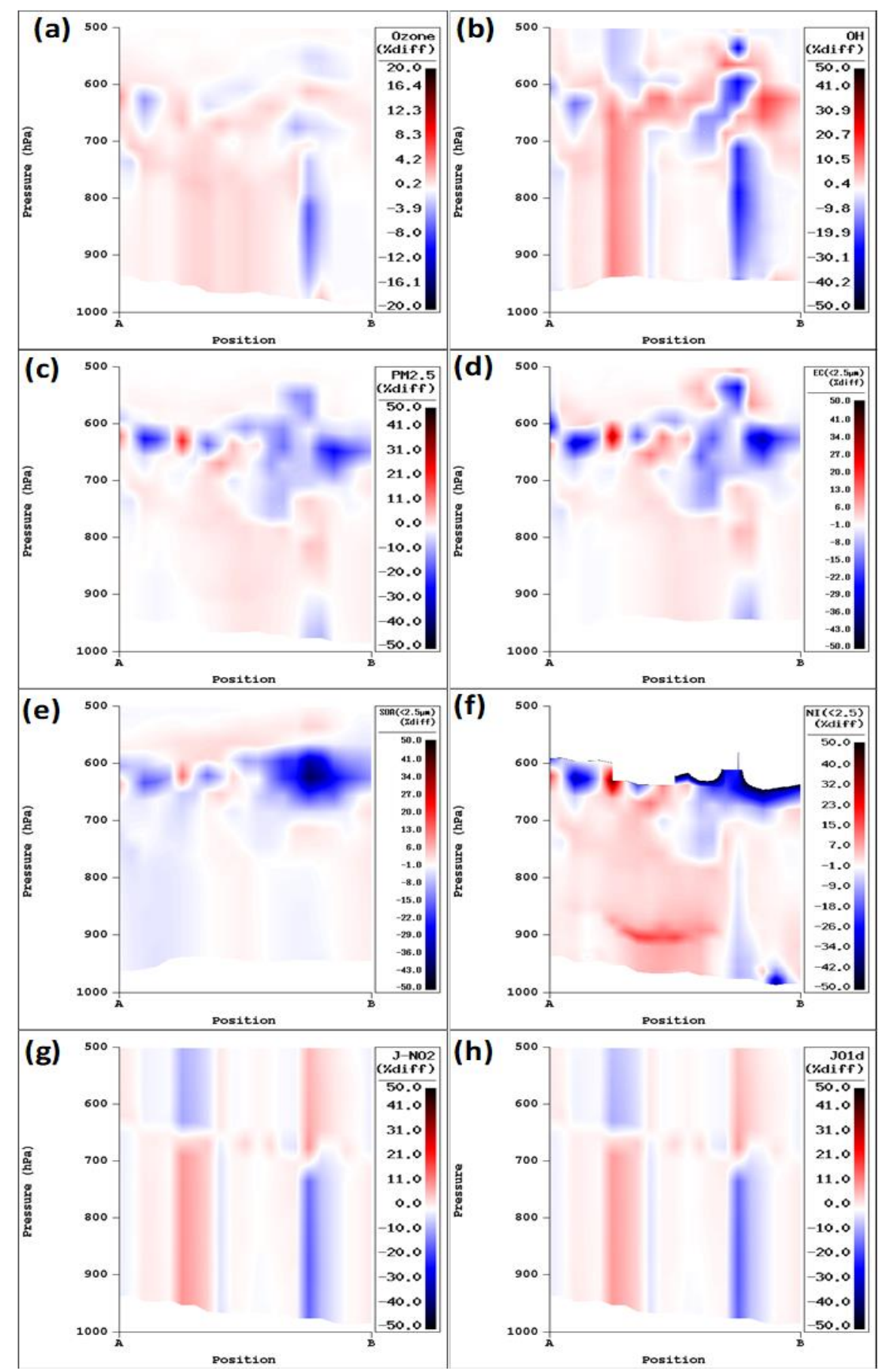

Figure 16: Cross sections of percentage difference in gas and ae rosol concentrations and photolysis rates with and without AOD calculations (with aerosol feedbacks) over the line shown in Fig. 14(c). Lac La Loche forest fire. June 25, 2018 at 23:00 UTC. a: ozone (ppb), b: hydroxyl radical $\left(\mu \mathrm{g} \mathrm{kg}^{-1}\right)$, c: PM2.5 $\left(\mu \mathrm{g} \mathrm{m}^{-3}\right)$, d: EC $\left(<2.5 \mu \mathrm{m}, \mu \mathrm{g} \mathrm{kg} \mathrm{k}^{-1}\right)$, e: nitrate $\left(<2.5 \mu \mathrm{m}, \mu \mathrm{g} \mathrm{m} \mathrm{m}^{-3}\right), \mathrm{f}: \mathrm{SOA}(<2.5 \mu \mathrm{m}$, $\left.\mu \mathrm{kg}^{-1}\right), \mathrm{g}: \mathrm{J}\left(\mathrm{NO}_{2}\right)\left(\mathrm{s}^{-1}\right), \mathrm{h}: \mathrm{J}\left(\mathrm{O}^{1} \mathrm{D}\right)\left(\mathrm{s}^{-1}\right)$. 

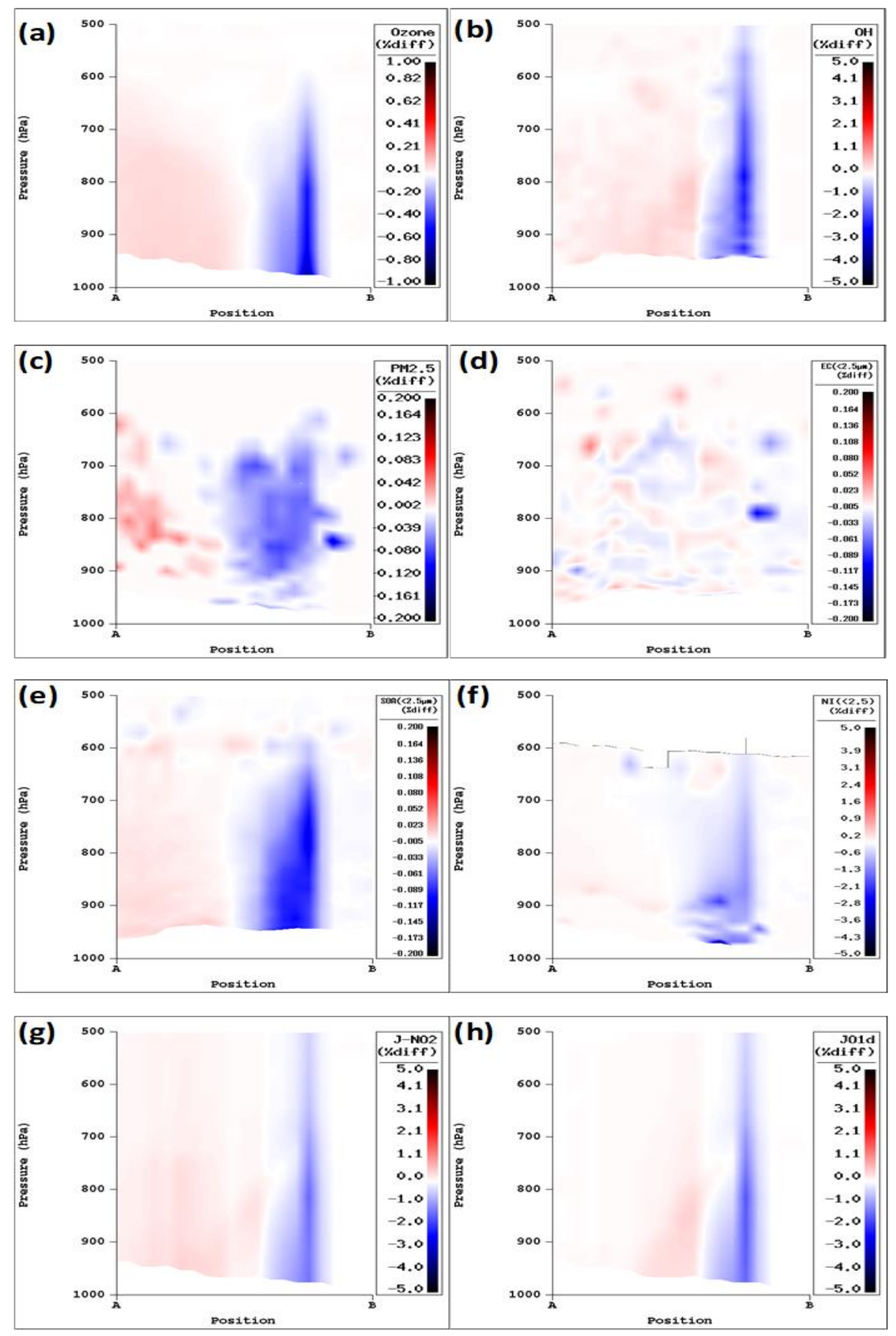

Figure 17: Cross sections of percentage difference in aerosol concentrations and photolysis rates with and without AOD calculations (no ae rosol feedbacks) over the line shown in Fig. 14(c). Lac La Loche forest fire. June 25, 2018 at 23:00 UTC. a: ozone (ppb), b: hydroxyl radical $\left(\mu \mathrm{g} \mathrm{kg}^{-1}\right)$, c: PM2.5 $\left(\mu \mathrm{g} \mathrm{m}^{-3}\right)$, d: EC $\left(<2.5 \mu \mathrm{m}, \mu \mathrm{g} \mathrm{kg}^{-1}\right)$, e: nitrate $\left(<2.5 \mu \mathrm{m}, \mu \mathrm{g} \mathrm{m} \mathrm{m}^{-3}\right), \mathrm{f}: \mathrm{SOA}(<2.5 \mu \mathrm{m}$, $\left.\mu \mathrm{kg}^{-1}\right), \mathrm{g}: \mathrm{J}\left(\mathrm{NO}_{2}\right)\left(\mathrm{s}^{-1}\right), \mathrm{h}: \mathrm{J}\left(\mathrm{O}^{1} \mathrm{D}\right)\left(\mathrm{s}^{-1}\right)$. 


\section{Summary and Conclusions}

A new lookup table for aerosoloptical properties based on a Mie scattering code was calculated and adopted within an improved version of the photolysis module in the GEM-MACH in-line chemical transportmodel, by interpolating the optical properties of aerosols into GEM-MACH wavelengths and size bins. The modified version of the photolysis module makes use of online interactive aerosol feedback for radiative transfer calculations. Additionally, for particle size bins with black carbon mass fraction of less than $40 \%$, a lensing correction factor to the black carbon absorption efficiency based on Bond et al. (2006) core-shell parameterizations was applied. The comparison of the improved version of MESSy-JVAL with the previous version showed significant improvements in the model performance with the implementation of the new photolysis module and adopting the online interactive aerosol concentrations in GEM-MACH. The calculated correlation coefficient, R, between the one-month hourly (June 2018) model and AERONET meas urements for all North American sites was 0.17 with the previous offline version of MESSY-JVAL and 0.37 with the improved version of the photolysis module.

A series of simulations using the improved photolysis module were performed for two months, January 2018 and June 2018, and the results were compared with satellite (MODIS-Terra) products, re-analysis products (MERRA-2) and ground-based measurements (AERONET). The monthly averaged AOD from the GEM-MACH output with the improved version of MESSy_JVAL showed an under-prediction of AOD over the common domain for both seasons. Detailed evaluations of AOD calculations over all North American AERONET sites for two months were performed and the model output was compared with observed AOD at each individual site. Model comparisons with observations at four Canadian AERONET sites showed good correlation with observations for both seasons. However, the correlation coefficient, R, shows better results for AERONET stations located further south in the domain with similar number of paired data points, e.g., Toronto $\left(43.79^{\circ} \mathrm{N},-\right.$ $\left.79.47^{\circ} \mathrm{W}\right)$ and Egbert $\left(44.23^{\circ} \mathrm{N},-79.78^{\circ} \mathrm{W}\right) \mathrm{vs}$. Saturna Island $\left(48.78^{\circ} \mathrm{N},-123.13^{\circ} \mathrm{W}\right)$ in summer and Fort McKay $\left(57.18^{\circ} \mathrm{N}\right.$, $-111.64^{\circ} \mathrm{W}$ ) in winter. Similarly, the NMB calculations show an over-prediction of AOD in Saturna Is land for both seasons and Fort McKay in winter, whereas there is an under-prediction of AOD in Toronto and Egbert for both seasons. In addition, we calculated a higher correlation coefficient between the model and measurements for urban AERONET sites for both simulation periods (e.g., Toronto vs. Fort McKay). Further investigations on the aerosol processes and emis sions at these sites is needed to assess the effects of different climatological and meteorological conditions on photoly sis rate calculations.

The sensitivity test to aerosol feedback demonstrates the effects of the model predicted aerosol distribution in the modified photolysis rate calculations. As shown in this study, there was up to $\pm 40 \%$ change in monthly averaged photolysis rate calculations with and without online aerosol feedback in the model, whereas with no aerosol feedback in the model this change is very small (-0.1\% to $0.1 \%$ ) between the runs with and without AOD calculations. The sensitivity tests to AOD calculations show a monthly average change of $\pm 10 \%$ in photolysis rate coefficients over the North American domain, while as shown in the forest fire case study this number can be as high as $\pm 50 \%$ in the fire plume. This study also showed the impact of aerosol feedbacks as parameterized in the model to be considerably greater than the effects of the AOD calculations (by a factor of 3 to 4) on the photoly sis rates over the entire domain. Furthermore, this study highlights the importance of model simulations of 
AOD where satellite observations are obscured by cloud cover. As shown in the case study, the simulated AOD over Lac La Loche forest fire of June 25, 2018, indicates a maximum value directly over the fire plume, while the same hots pot is not detected with the same intensity by MODIS-Terra, possibly due to cloud obscuring surface in satellite retrieval.

Further investigation of the effects of the improved photolysis module with a nested configuration of GEM-MACH 10-km domain to a $2.5 \mathrm{~km}$ Athabasca Oil Sands domain is needed for more detailed comparisons of modeloutput with observations under the OilSands Monitoring Program, 2018 aircraft campaign. This new model capability will also enable us to use model predicted AOD on regional scales over the boreal forest to assess fut ure improvements in biogenic VOC emis sions and SOA processes in GEM-MACH, by comparing with clear-sky satellite-derived AOD.

Data availability: GEM-MACH, the atmospheric chemistry library for the GEM numerical atmospheric model (C20072013, Air Quality Research Division and National Prediction Operations Division, Environment and Climate Change Canada), is a free software which can be redistributed and/or modified under the terms of the GNU Lesser General Public License as published by the Free Software Foundation - either version 2.1 of the license or any later version. The modified MACH (chemistry) code with the improved photolysis module can be downloaded from the Zenodo website: https://zenodo.org/record/5042514\#.YNtY8hGSmPo. The GEM (meteorology) code (Canadian Meteorological Centre, 2018) is available to download from the website: https://github.com/mfvalin?tab=repositories (last access: 25 June 2021). The executable for GEM-MACH is obtained by providing the chemistry library to GEM when generating its executable. Many of the emissions data used in our model are available online at ECCC web page at http://donnees.ec.gc.ca/data/air/monitor/source-emis sions-monitoring-oil-sands-region/source-emissions-oil-sandsregion/?lang=en (ECCC, 2018) and more recent updates may be obtained by contacting Junhua Zhang or Mike Moran (junhua.zhang@ec.gc.ca; mike.moran@ec.gc.ca). The model output is available upon request to Craig Stroud (craig.stroud@ec.gc.ca). The AERONET version 3 AOD datasets are publicly available from the AERONET website (https://aeronet.gsfc.nasa.gov/, last access: 5 February 2020). Terra MODIS level-3 Atmospheric Daily Global Product of AOD, MERRA-2 AerosolOpticalDepth Analy sis V5.12.4, and MERRA-2 AerosolScattering AOT were obtained from the publicly accessible Goddard Earth Sciences Data and Information Services Centre platform (GIOVANNI: https://giovanni.gsfc.nasa.gov/giovanni/, last access: 1 October 2020).

Author contributions: CAS and MM were responsible for the design, calculations and methodology of this study. MM developed and implemented the improved code into the photoly sis module in GEM-MACH, performed the analysis of the model output and wrote the manuscript under the supervision of CAS, with as sistance from PAM. CS calculated the initial version of the updated lookup table for aerosol optical properties based on the model developed by CM. AA provided support with GEM-MACH model and CFFEPS emissions. MDM contributed emissions data used in the modelling. IA and XZ provided and performed data analysis with AERONET measurements. JC developed the previous off-line version of the photolysis module in GEM-MACH and is the lead developer of the ECCC FireW ork System. 
Competing interests: The authors declare that they have no conflict of interest.

Acknowledgements: The authors thank Balbir Pabla, Verica Savić-Jovčić, Philip Cheung and Shuzhan Ren of Air Quality Research Division of Environment and Climate Change Canada for their expertise and contributions in this project. We thank NASA AERONET programme for supporting the AOD observation data in this project. The satellite and data assimilation products used in this study were produced with the Giovanni online data system, developed and maintained by the NASA GES DISC (https://giovanni.gsfc.nasa.gov/giovanni/). We acknowledge the mission scientists and Principal Investigators for the satellite and re-analysis data used in this research effort. This work is fully funded under the Oil Sands Monitoring (OSM) Program. It is independent of any position of the OSM Program.

\section{References:}

Alvarado, M. J., Lonsdale, C. R., Yokelson, Robert, Akagi, Sheryl Kashi, Coe, H., Craven, J. S., Fischer, E. V., McMeeking,

G. R., Seinfeld, J. H., Soni, T., Taylor, J. W., Weise, D. R., and Wold, C. E.: Investigating the links between ozone and organic aerosol chemis try in a biomas s burning plume froma prescribed fire in California chaparral, Atmos. Chem. Phys., 15, 66676688, doi:10.5194/acp-15-6667-2015., 2015

Alvarado, M. J., Lons dale, C. R., Macintyre, H. L., Bian, H., Chin, M., Ridley, D. A., Heald, C. L., Thornhill, K. L., Anderson, B. E., Cubison, M.J., Jimenez, J. L., Kondo, Y., Sahu, L. K., Dibb, J. E., and Wang, C.: Evaluating model parameterizations of submicron aerosol scattering and absorption with in situ data from ARCTAS 2008, Atmos. Chem. Phys., 16, 9435-9455, https://doi.org/10.5194/acp-16-9435-2016, 2016.

Acker, J.G. and Leptoukh, G., “Online Analysis Enhances Use ofNASA Earth Science Data”, Eos, Trans. AGU, Vol. 88, No. 2 (9 January 2007), pages 14 and 17.

Anderson, B. E., Cofer, W. R., Bagwell, D. R., Barrick, J. W., Hudgins, C. H., Brunke, K. E.: Airborne observations of aircraft aerosolemis sions 1: total non-volatile particle emission indices, Geophys. Res. Lett., 25, 1689-1692, 1998.

Anderson, K. and cast of thousands: CFFEPS v2.03, Canadian Forest Service, Natural Resources Canada, Zenodo, https://doi.org/10.5281/zenodo.2579383, 2019.

Anderson, K. R., Pankratz, A., and Mooney, C.: A thermodynamic approach to estimating smoke plume heights, in Ninth Symposium on Fire and Forest Meteorology, American Meteorological Society, Palm Springs, CA, USA, available at: https://cfs.nrcan.gc.ca/publications?id=33463, 2011, last access: 22 October 2020.

APEI: Air Pollutant Emissions Inventory, https://www.canada.ca/en/environment-climate-change/services/pollutants/airemissions-inventory-overview.html, last access 16 March 2021.

Barnaba, F., Putaud, J. P., Gruening, C., dell'Acqua, A., and Dos Santos, S.: Annual cycle in co-located in situ, total-colum, and height-resolved aerosol observations in the Po Valley (Italy): Implications for ground-level particulate matter mass concentration es timation fromremote sensing, J. Geophys. Res., 115, D19209, doi:10.1029/2009JD013002, 2010. 
Bohren, C. F., \& Huffman, D. R. (1983). Absorption and scattering of light by small particles . New York: Wiley.

Bond, T. C. and Bergstrom, R. W:Light Absorption by Carbonaceous Particles: An Investigative Review, Aerosol Science and Technology, 40:1, 27-67, DOI: 10.1080/02786820500421521, 2006.

Bond, T. C., Habib, G., and Bergstrom, R. W .: Limitations in the enhancement of visible light absorption due to mixing state,

J. Geophys. Res., 111, D20211, doi: 10.1029/2006JD007315, 2006.

Bozzo, A., Benedetti, A., Flemming, J., Kipling, Z., and Rémy, S.: An aerosol climatology for global models based on the tropospheric aerosol scheme in the Integrated Forecasting Sy stemofECMWF, Geosci. ModelDev., 13, 1007-1034, 2020.

Braslau, N. and Dave, J. N.: Effect of aerosols on the transfer of solar energy through realistic model atmospheres. Part I: Nonabsorbing aerosols, J. Appl. Meteor., 12, 601-615, 1973.

Buchard, V., da Silva, A. M., Colarco, P. R., Darmenov, A., Randles, C. A., Govindaraju, R., Torres, O., Campbe 1l, J., and Spurr, R.: Using the OMI aerosol index and absorption aerosol optical depth to evaluate the NASA MERRA Aerosol Reanalysis, Atmos. Chem. Phys., 15, 5743-5760, https://doi.org/10.5194/acp-15-5743-2015, 2015.

Buchard, V., da Silva, A.M., Randles, C.A., Colarco, P., Ferrare, R., Hair, J., Hostetler, C., Tackett, J., W inker, D.: Evaluation of the surface $\mathrm{PM}_{2.5}$ in version 1 of the NASA MERRA Aerosol Reanaly sis over the United States. Atmos. Environ., 125, 100111, doi: https://doi.org/10.1016/j.atmosenv.2015.11.004, 2016.

Buchard, V., Randles, C.A., da Silva, A. M., Darmenov, A, Colarco, P. R., Govindaraju, R., Ferrare, R., Hair, J., Beyersdorf, A. J., Ziemba, L. D., Yu, H.: The MERRA-2 Aerosol Reanalysis, 1980 Onward. Part II: Evaluation and Case Studies, J. Climate, 30 (17): 6851-6872. https://doi.org/10.1175/JCLI-D-16-0613.1, 2017.

Canadian Meteorological Centre: gemdyn and rpnphy repositories, available

at: https://github.com/mfvalin?tab=repositories, last access: 25 June 2021.

Canadian Wildland Fire Information System(CWFIS), http://cwfis.cfs.nrcan.gc.ca, last access: 1 December 2020.

Caron, J.-F. and Anselmo, D.: Regional Deterministic Prediction System(RDPS) Technical Note, Environment Canada, Dorval, Quebec, $\quad 40 \quad$ Canada, $\quad$ available at: http://collaboration.cmc.ec.gc.ca/cmc/cmoi/product_guide/docs/lib/technote_rdps-400_20141118_e.pdf, 2014, last access:15 785 June 2018.

Chang, J., Brost, R. A., Is aksen, I. S. A., Madronich, S, Middleton, P., Stockwell, W. R., and Walcek, C. J.: A three-dimensional Eulerian acid deposition model: Physical concepts and formation, J. Geophys. Res., 92(D12), 14681-14700, doi:10.1029/JD092iD12p14681, 1987.

Charron, M., Polavarapu, S., Buehner, M., Vaillancourt, P. A., Charette, C., Roch, M., Morneau, J., Garand,L., Aparicio, J. 790 M., MacPherson, S., Pellerin, S., St-James, J., and Heilliette, S.: The Stratospheric Extension of the Canadian Global Determinis tic Medium-Range Weather Forecasting System and Its Impact on Tropospheric Forecasts, Mon. Weather Rev, 140, 1924-1944, 2012, https://doi.org/10.1175/MWR-D-11-00097.1. 
Chen, J., Anderson, K., Pavlovic, R., Moran, M. D., Englefield, P., Thompson, D. K., Munoz-Alpizar, R., and Landry, H.: The FireW ork v2.0 air quality forecast system with biomass burning emis sions from the Canadian Forest Fire Emis sions Prediction Systemv2.03, Geosci. ModelDev., 12, 3283-3310, https ://doi.org/10.5194/gmd-12-3283-2019, 2019.

Chen, J., Pendlebury, D., Gravel, S., Stroud, C., Ivanova, I., DeGranpré, J., Plummer, D.: Development and Current Status of the GEM-MACH-Global Modelling System at the Environment and Climate Change Canada. In: Mensink C., Gong W., Hakami A. (eds) Air Pollution Modeling and its Application XXVI. ITM 2018. Springer Proceedings in Complexity. Springer, Cham. https://doi.org/10.1007/978-3-030-22055-6_18, 2020.

Chin, M., Ginoux, P., Kinne, S., Torres, O., Holben, B.N., Duncan, B.N., Martin, R.V., Logan, J.A., Higurashi, A., Nakajima, T.: Tropospheric aerosol optical thickness from the GOCART model and comparisons with satellite and sun photometer measurements. J. Atmos. Sci., 59, 461-483, doi: https://doi.org/10.1175/1520-0469(2002)059<0461:TAOTFT>2.0.CO;2, 2002.

Colarco,P., da Silva, A., Chin, M. and Diehl, T.: Online simulations of global aerosol distributions in the NASA GEOS-4 model and comparisons to satellite and ground-based aerosol optical depth.J. Geophys. Res., 115, D14207, doi:https://doi.org/10.1029/2009JD012820, 2010.

Côté, J., Gravel, S., Méthot, A., Patoine, A., Roch, M., and Staniforth, A.:The operational CMC/MRB global environmental multiscale (GEM) model. Part 1: design considerations and formulation, Mon. Weather Rev., 126, 1373-1395, 1998 a.

Côté, J., Desmarais, J.-G., Gravel, S., Méthot, A., Patoine, A., Roch, M., and Staniforth, A.: The operational CMC-MRB g lobal environment multis cale (GEM) model. Part II: results, Mon.Weathre Rev., 126, 1397-1418, 1998b.

Curci, G., Hogrefe, C., Bianconi, R., Im, U., Balzarini, A., Baró, R., Brunner, D., Forkel, R., Giordano, L., Hirtl, M., Honzak, L., Jimenez-Guerrero, P., Knote, C., Langer, M., Makar,P., Pirovano, G., Camaño, J., García, R., Syrakov, D., Galmarini, S.: Uncertainties of simulated aerosoloptical properties induced by assumptions on aerosol physical and chemical properties: An AQMEII-2 pers pective. A tmospheric Environment. 115. 10.1016/j.atmosenv.2014.09.009, 2015.

815 Dave, J. V.: Development of programs for computing characteristics of ultraviolet radiation, Fin al Reportunder Contract NAS 5-21680, NASA Report CR-139134, National Aeronautics and Space Administration, Goddard Space Flight Center, Greenbelt, Maryland, NTIS \# N75-10746/6SL, 27 pp., 1972.

DeMore, W. B., Sander, S. P., Molina, M. J., Golden, D. M., Hampson, R. F., Kurylo, M. J., Howard, C. J., and Ravis hankara, A. R.: Chemical Kinetics and Photochemical Data for Use in Stratospheric Modeling, Evaluation Number 8, National Aeronautics and Space Administration, Jet Propulsion Laboratory, California Institute of Technology, Pasadena, California, 266 pp., 1988.

Dorsey, N. E.: Properties of ordinary water-substance in all its phases: water vapor, water and all the ices, pp. 332-338, Am. Chem. Soc. Monograph Series, Reinhold Publishing Corp., New York, 1940.

Emmons, L. K., Walters, S., Hes s, P. G., Lamarque, J.-F., Pfister, G. G., Fillmore, D., Granier, C., Guenther, A., Kinnison, D., 
of the Model for Ozone and Related chemical Tracers, version 4 (MOZART-4), Geosci. Model Dev., 3, 43-67, https://doi.org/10.5194/gmd-3-43-2010, 2010.

Escribano, J., Gallardo, L., Rondanelli, R. and Choi, Y.-S.: Satellite retrievals of aerosol optical depth over a subtropical urban area: The role of stratification and surface reflectance, Aerosol and Air Quality Research, 14, 596-607, 2014. Eyth, A., Mason, R., and Zubrow, A.: Development and Status ofEPA's 2011 Modeling Platform, 12th CMAS Conference, 28-30 October, Chapel Hill, North Carolina, available at: https://www.cmascenter.org/conference//2013/slides/eyth_ development_status_2013.pptx, 2013.

Fores try CanadaFire Danger Group, Development and structure of the Canadian Forest Fire Behavior Prediction System. Inf. Rep ST-X-3. Forestry Canada, Science and Sustainable Development Directorate, Ottawa, Ont., 63 pp, 1992.

835 Fung, C.S., Misra, P.K., Bloxam, R., and Wong S.: A numerical experiment on the relative importance of $\mathrm{H}_{2} \mathrm{O}_{2}$ and $\mathrm{O}_{3}$ in aqueous conversion of $\mathrm{SO}_{2}$ to $\mathrm{SO}_{4}{ }^{2-}$. Atmos. Environ., 25A, 411--423, 1991.

Gan, C.-M., Pleim, J., Mathur, R., Hogrefe, C., Long, C. N., Xing, J., Roselle, S., and Wei, C.: Assessment of the effect of air pollution controls on trends in shortwave radiation over the United States from 1995 through 2010 from multiple observation networks, Atmos. Chem. Phys., 14, 1701-1715, doi:10.5194/acp-14-1701-2014, 2014a.

Gan, C.-M., Binkowski, F., Pleim, J., Wong, D., Mathur, R. and Gilliam, R.: As sessment of the Aerosol Optics Component of the Coupled WRF-CMAQ Model using CARES Field Campaign data and a Single Column Model, Atmos. Environ., 115, 670-682, doi:10.1016/j.atmosenv.2014.11.028, 2014b.

Gan, C.-M., Pleim, J., Mathur, R., Hogrefe, C., Long, C. N., Xing, J., Wong, D., Gilliam, R., and Wei, C.: Ass sessment of longterm WRF-CMAQ simulations for understanding direct aerosol effects on radiation "brightening" in the United States, Atmos. Chem. Phys., 15, 12193-12209, https://doi.org/10.5194/acp-15-12193-2015, 2015.

Gelaro, R., McCarty, W., Suárez, M.J., Todling, R., Molod, A., Takacs, L., Randles, C.A., Darmenov, A., Bosilovich, M.G., Reichle, R., Wargan, K., Coy, L., Cullather, R., Draper, C., Akella, S., Buchard, V., Conaty, A., da Silva, A.M., Gu, W., Kim, G-.K., Koster, R., Lucchesi, R., Merkova, D., Nielsen, J.E., Partyka, G., Pawson, S., Putman, W., Rienecker, M., Schubert, S.D., Sienkiewicz, M.,Zhao, B.: The Modern-Era Retrospective Analysis for Research and Applications, Version 2 (MERRA-

2), J. Climate, 30 (14): 5419-5454, https://doi.org/10.1175/JCLI-D-16-0758.1, 2017.

Giles, D., Sinyuk, A., Sorokin, M., Schafer, J., Smirnov, A., Slutsker, I., Eck, T., Holben, B., Lewis, J., Campbell, J., Welton, E., Korkin, S., Lyapustin, A.: Advancements in the Aerosol Robotic Network(AERONET) Version 3 database - Automated near-real-time quality control algorithm with improved cloud screening for Sun photometer aerosol optical depth (AOD) measurements. Atmospheric Measurement Techniques. 12. 169-209. 10.5194/amt-12-169-2019, 2019.

Girard, C., Plante, A., Desgagné, M., Mctaggart-Cowan, R., Côté, J., Charron, M., Gravel, S., Lee, V., Patoine, A., Qaddouni, A., Roch, M., Spacek, L., Tanguay, M., Vaillancourt, P. A., and Zadra, A.: Staggered vertical discretization of the canadian environmental multiscale (GEM) model using a coordinate of the log-hydrostatic-pressure type, Mon. Weather Rev., 142, 1183-1196, 2014. 
Global Modeling and Assimilation Office (GMAO) (2015), MERRA-2 instM_2d_gas_Nx:2d, Monthly mean, Instantaneous,

Single-Level, Assimilation, Aerosol Optical Depth Analysis V5.12.4, Greenbelt, MD, USA, Goddard Earth Sciences Data and Information Services Center (GES DISC), Accessed: October 06, 2020, 10.5067/XOGNBQEPLUC5, Access 1 November 2020.

Global Modeling and Assimilation Office (GMAO) (2015), MERRA-2 tavg1_2d_aer_Nx: 2d,1-Hourly, Time-averaged, Single-Level, Assimilation, AerosolDiagnostics V5.12.4, Greenbelt, MD, USA, Goddard Earth Sciences Data and Information

Services Center (GES DISC), Accessed: October 06, 2020, 10.5067/KLICLTZ8EM9D, Access 1 November 2020.

Global Modeling and Assimilation Office (GMAO) (2015), MERRA-2 tavgM_2d_aer_Nx: 2d, Monthly mean, Timeaveraged, Single-Level, Assimilation, Aerosol Diagnostics V5.12.4, Greenbelt, MD, USA, Goddard Earth Sciences Data and Information Services Center (GES DISC), Accessed: October 06, 2020, 10.5067/FH9A0MLJPC7N, Access 1 November 2020. Gong, S. L., Barrie, L. A., and Lazare, M.: Canadian Aerosol Module (CAM), a size-segregated simulation of atmospheric aerosol processes for climate and air quality models 2, Global sea-salt aerosol and its budgets, J. Geophys. Res., 107, 4779, https://doi.org/10.1029/2001JD002004, 2003a.

Gong, S. L., Barrie, L. A., Blanchet, J.-P., von Salzen, K., Lohmann, U., Lesins, G., Spacek, L., Zhang, L. M., Girard, E., Lin, H., Leaitch, R., Leighton, H., Chylek, P., and Huang, P., Canadian Aerosol Module: a size-segregated simulation of atmospheric aerosol processes for climate and air quality models,1. Module development, J. Geophys. Res. 108, 400, https://doi.org/10.1029/2001JD002002, 2003b.

Gong, W., Dastoor, A. P., Bouchet, V. S., Gong, S. L., Makar, P. A., Moran, M. D., Pabla, B., Menard, S., Crevier, L.-P., Cousineau, S., and Venkatesh, S.: Cloud processing of gases and aerosols in a regional air quality mod el (AURAMS), Atmos. Res., 82, 248-275, 2006.

Gong, W., Makar, P.A., Zhang, J., Milbrandt, J., Gravel, S.: Modelling aerosol-cloud- meteorology interaction: a case study with a fully coupled air-quality model (GEM-MACH). Atmos. Environ. 115, 695-715, https://doi.org/10.1016/j.atmosenv.2015.05.062,2015.

Gosse, S. F., Wang, M., Labrie, D., and Chylek, P.: Imaginary part of the refractive index of sulfates and nitrates in the 0.72.6- $\mu \mathrm{m}$ spectral region, Appl. Opt., 36, 3622-3634, 1997.

Hansen, J. E., and L. D. Travis, Light scattering in planetary atmospheres, Space. Sci. Rev., 16, 527-610, 1974.

885 Healy, R., Riemer, N., Wenger, J., Murphy, M., West, M., Poulain, L., et al.: Single particle diversity and mixing state measurements. Atmospheric Chemis try and Physics, 14(12), 6289-6299, 2014.

IPCC, 2018: Global warming of $1.5^{\circ} \mathrm{C}$. An IPCC Special Report on the impacts of global warming of $1.5^{\circ} \mathrm{C}$ above preindustrial levels and related global greenhouse gas emis sion pathways, in the context of strengthening the global response to the threat of climate change, sustainable development, and efforts to eradicate poverty [V. Mas son-Delmotte, P. Zhai, H. O. 890 Pörtner, D. Roberts, J. Skea, P.R. Shukla, A. Pirani, W. Moufouma-Okia, C. Péan, R. Pidcock, S. Connors, J. B. R. Matthews, Y. Chen, X. Zhou, M. I. Gomis, E. Lonnoy, T. Maycock, M. Tignor, T. Waterfield (eds.)]. In Press. 
Jacob, D. J., Crawford, J. H., Maring, H., Clarke, A. D., Dibb, J. E., Emmons, L. K., Ferrare, 30 R. A., Hostetler, C. A., Ru s sell, P. B., Singh, H. B., Thompson, A. M., Shaw, G. E., McCauley, E., Pederson, J. R., and Fisher, J. A.: The Arctic Research of the Composition of 2 the Troposphere from Aircraft and Satellites (ARCTAS) mis sion: design, execution, and first 3 results, Atmos. Chem. Phys., 10, 5191-5212, doi:10.5194/acp-10-5191-2010, 2010.

Jacobson, M. Z., (2005). Fundamentals of Atmospheric Modeling ( $\left.2^{\text {nd }} \mathrm{ed}\right)$. Cambridge: Cambridge University Press. Doi: 10.1017/CBO9781139165389.

Jacobson, M. Z., A physically-based treatment of elemental carbon optics: Implications for global direct forcing of aerosols. Geophys. Res. Lett. 27, 217-220, https://doi.org/10.1029/1999GL010968, 2000.

Jacobson, M. Z., Strong radiative heating due to the mixing state of black carbon in atmospheric aerosols. Nature 409, 695697, https://doi.org/10.1038/35055518, 2001.

Jeong, G.-R.: Weather effects of aerosols in the global forecast model, Atmosphere, 11, 850, doi:10.3390/atmos 11080850, 2020.

Jöckel, P., Sander, R., Kerkweg, A., Tost, H., and Lelieveld, J.: Technical Note: The Modular Earth Submodel System

(MESSy) - a new approach towards Earth System Modeling, Atmos. Chem. Phys., 5, 433-444, doi:10.5194/acp-5-433-2005, 2005.

Kelly, J., Makar, P. A., and Plummer, D. A.: Projections of mid-century summer air-quality for North America: effects of changes in climate and precursor emissions, Atmos. Chem. Phys., 12, 5367-5390, https://doi.org/10.5194/acp-12-5367-2012, 2012 .

910 Kou, L.: Black carbon: Atmospheric measurements and radiative effect, Ph. D. thesis, Dalhousie Univ., Halifax, NS, 144 pages, 1996.

Landgraf, J. and Crutzen, P. J.: An efficient method for online calculations of photolysis and heating rates, J. Atmos. Sci., 55, 863-878, 1998.

Laskina, O., Morris H.S., Grandquist, J.R., Qin, Z., Stone, E.A., Tivanski, A.V., and Gras sian, V.H.: Size Matters in the Water

Uptake and Hygroscopic Growth of Atmospherically Relevant Multicomponent Aerosol Particles, J. Phys. Chem. A., 119 (19), 4489-4497, DOI: 10.1021/jp510268p, 2015.

Latimer, Robyn N. C. and Martin, R. V.: Interpretation of measured aerosol mass scattering efficiency over North America using a chemical tran sport model, Atmos. Chem. Phys., 19, 2635-2653, https://doi.org/10.5194/acp-19-2635-2019, 2019.

Lee, B.S. \& Alexander, M., Hawkes, B., Lynham, T.J., Stocks, B., Englefield, P. Information Sys tems in Support of Wildland

Fire Management Decision Making in Canada. Computers and Electronics in Agriculture. 37. 185-198. 10.1016/S01681699(02)00120-5, 2002.

Lei, T., Zuend, A., Wang W.G., Zhang, Y.H., and Ge, M.F.:Hyg ros copicity of org anic compounds from biomas s burning and their influence on the water uptake of mixed organic ammonium sulfate aerosols, Atmos. Chem. Phys., 14, 11165-11183, 2014. 
Li, J., Barker, H.W.: A radiation algorithm with correlated k-dis tribution. Part I: local thermal equilibrium. J. Atmos. Sci. 62, 286-309, 2005.

Liu, D., Whitehead, J., Alfarra, M.: Black-carbon absorption enhancement in the atmosphere determined by particle mixing state. Nature Geosci., 10, 184-188, https://doi.org/10.1038/ngeo2901, 2017.

Lurmann, F. W., Lloyd, A. C., and Atkinson, R.: A chemical mechanism for use in long range transport/acid deposition computer modeling, J. Geophys. Res., 91, 10905-10936, 1986.

Majdzadeh M., Stroud C.A. and GEM-MACH Development Team: GEM-MACH: Aerosol Effect (with Core-Shell Parameterization) on MESSy-JVAL Photolysis, Zenodo, https://zenodo.org/record/5042514\#.YNtZtRGSmPp, DOI: 10.5281/zenodo.5042514, last access: 29 June 2021.

Makar, P. A., Bouchet, V. S., and Nenes, A.: Inorg anic Chemistry Calculations using HETV - A Vectorized Solver for the $\mathrm{SO}_{4}^{2-}-\mathrm{NO}_{3}^{-}-\mathrm{NH}_{4}^{+}$systembased on the ISORROPIA Algorithms, Atmos. Environ., 37, 2279-2294, 2003.

Makar, P. A., Gong,W., Milbrandt, J., Hogrefe, C., Zhang, Y., Curci,G., Zabkar, R., Im, U., Balzarini, A., Baro, R., Bianconi, R., Cheung, P., Forkel, R., Gravel, S., Hirtl, H., Honzak, L., Hou, A., Jimenz-Guerrero, P., Langer, M., Moran, M. D., Pabla, B., Perez, J. L., Pirovano, G., San Jose, R., Tuccella, P., Werhahn, J., Zhang, J., and Galmarini, S. : Feedbacks between air pollution and weather, part 1: Effects on weather, Atmos. Environ., 115, 442-469, 2015a.

940 Makar, P. A., Gong, W., Hogrefe, C., Zhang, Y., Curci, G., Zabkar, R., Milbrandt, J., Im, U., Balzarini, A., Baro, R., Bianconi, R., Cheung, P., Forkel, R., Gravel, S., Hirtl, H., Honzak, L., Hou, A., Jimenz-Guerrero, P., Langer, M., Moran, M. D., Pabla, B., Perez, J. L., Pirovano, G., San Jose, R., Tuccella, P., Werhahn, J., Zhang, J., and Galmarini S.: Feedbacks between air pollution and weather, part 2: Effects on chemistry, Atmos. Environ., 15, 499-526, $2015 \mathrm{~b}$.

Makar, P.A., Akingunola, A., Aherne, J., Cole, A.S., Aklilu, Y., Zhang, J., Wong, I., Hayden, K., Li, S.-M., Kirk, J., Scott, K., 945 Moran, M.D., Robichaud, A., Cathcart, H., Baratzedah, P., Pabla, B., Cheung, P., and Zheng, Q.:Estimates of exceedances of critical loads for acidifying deposition in Alberta and Saskatchewan. Atmos. Chem. Phys., 18, 9897-9927, https://doi.org/10.5194/acp-18-9897-2018, 2018.

Markovic, M., Jones, C., Vaillancourt, P., Paquin, D., Winger, K., and Paquin-Ricard, D.: An evaluation of the surface radiation budget over North America for a suite of regional climate models against surface station observations. Clim. Dyn., 31, 779794. 10.1007/s00382-008-0378-6, 2008.

Matsumi, Y., Comes, F. J., Hancock, G., Hofzumahaus, A., Hynes, A. J., Kawasaki, M., and Ravishankara, A. R.: Quantum yields for production of $\left({ }^{1} \mathrm{D}\right)$ in the ultraviolet photoly sis of ozone: Recommendation based on evaluation of laboratory data, J. Geophys. Res., 107(D3), 10.1029/2001JD000510, 2002.

Mätzler, C.: MATLAB functions for Mie scattering and absorption, Res. Rep. 2002-08, Inst. für Angew. Phys., Bern, 2002. 955 McLinden, C. A., McConnell, J. C., Griffioen, E., and McElroy, C. T.: A vector radiative-transfer model for the Odin/OSIRIS project, Can. J. Phys., 80, 375-393, 2002. 
McMeeking, G. R., Hamburger, T., Liu, D., Flynn, M., Morgan, W. T., Northway, M., Highwood, E. J., Krejci, R., Allan, J. D., Minikin, A., and Coe, H.: Black carbon measurements in the boundary layer over western and northern Europe, Atmos. Chem. Phys., 10, 9393-9414, doi:10.5194/acp-10-9393-2010, 2010.

Moran, M. D., Ménard, S., Talbot, D., Huang, P., Makar, P. A., Gong, W., Landry, H., Gravel, S., Gong, S., Crevier, L.-P., Kallaur, A., and Sassi, M., 2011: Particulate-matter forecasting with GEMMACH15, a new Canadian air-quality forecast model, in: Air Pollution Modelling and Its Application XX, edited by: Steyn, D. G. and Rao, S. T., Springer, Dordrecht, 289292, 2010.

Pavlovic, R., Chen, J., Anderson, K., Moran, M. D., Beaulieu, P. A., Davignon, D., Cousineau, S.: The FireW ork air quality

forecast system with near-real-time biomass burning emis sions: Recent developments and evaluation of performance for the 2015 North American wildfire season. Journal of the Air \& Was te Management Association, 66(9), 819-841, 2016.

Péré, C., Mallet, M., Bessagnet, B., Pont, V.: Evidence of the aerosol core-shell mixing state over Europe during the heat wave of summer 2003 by using CHIMERE simulations and AERONET inversions. Geophys. Res. Lett, 36, L09807, doi:10.1029/2009GL037334, 2009.

Peterson, J. T.: Calculated actinic fluxes $(290-700 \mathrm{~nm})$ for air pollution photochemistry applications, US Environmental Protection Agency Report Number EPA-600/4-76-025, 55 pp., 1976.

Platnick, S., Hubanks, P., Meyer, K., and King, M.D. 2015: MODIS AtmosphereL3 Monthly Product(08_L3). NASA MODIS Adaptive Processing System, Goddard Space Flight Center, http://dx.doi.org/10.5067/MODIS/MOD08_M3.006(Terra), Access 1 December 2020.

Randles, C.A., da Silva, A.M., Buchard, V., Colarco, P.R., Darmenov, A., Govindaraju, R., Smirnov, A., Holben, B., Ferrare, R., Hair, J., Shinozuka, Y., Flynn, C.J.: The MERRA-2 Aerosol Reanalysis, 1980 Onward. Part I: System Description and Data As similation Evaluation, J. Climate, 30 (17): 6823-6850, https://doi.org/10.1175/JCLI-D-16-0609.1, 2017.

Riemer, N., Ault, A. P., West, M., Craig, R. L. and Curtis, J. H.: Aerosol mixing state: Measurements, modeling, and impacts. Reviews of Geophysics, 57, 187- 249. https://doi.org/10.1029/2018RG000615, 2019.

Rienecker, M. M., and Coauthors: MERRA: NASA's Modern-Era Retrospective Analysis for Research and Applications. J. Climate, 24, 3624-3648, doi: https://doi.org/10.1175/JCLI-D-11-00015.1, 2011.

Sander, R., Baumgaertner, A., Gromov, S., Harder, H., Jöckel, P., Kerkweg, A., Kubistin, D., Regelin, E., Riede, H., Sandu, A., Taraborrelli, D., Tost, H., and Xie, Z.-Q.: The atmos pheric chemis try box model CAABA/MECCA-3.0, Geosci. Model Dev., 4, 373-380, doi:10.5194/gmd-4-373-2011, 2011a.

Sander, R., Jöckel, P., Kirner, O., Kunert, A. T., Landgraf, J., and Pozzer, A.: The photolysis module JVAL-14, compatible with the MESSy standard, and the JVal PreProcessor (JVPP), Geosci. ModelDev., 7, 2653-2662, https://doi.org/10.5194/gmd7-2653-2014, 2014.

Schuster, G. L., Lin, B. and Dubovik, O.: Remote sensing of aerosol water uptake, Geophys. Res. Lett., 36, L03814, doi:10.1029/2008GL036576, 2009. 
https://doi.org/10.5194/gmd-2021-172

Preprint. Discussion started: 8 July 2021

(c) Author(s) 2021. CC BY 4.0 License.

(c) (i)

Shettle, E. P., and Fenn, R. W.: Models for the aerosols of the lower atmosphere and the effects of humidity variations on their optical properties, AFGL-TR-79-0214, 94 pages, Hanscom AFB, MA, USA, 1979.

Slingo, A.: A GCM parameterization for the shortwave radiative properties of water clouds. J. Atmos. Sci., 46, 1419-1427. Stamnes, K., and S.-C. Tsay, 1990: Optimum spectral resolution for computing atmospheric heating and photodissociation rates. Planet. Space Sci., 38, 807-820, 1989.

Stevens, R.; Das toor, A. A Review of the Representation of Aerosol Mixing State in Atmospheric Models. Atmosphere, 10(4), 168, https://doi.org/10.3390/atmos10040168, 2019.

Tang, I. N., Wong, W. T., and Munkelwitz, H. R.: The relative importance of atmospheric sulfates and nitrates in visibility reduction, Atmos. Env., 15(12), 2463-2471, 1981.

Tang, I. N. and Munkelwitz, H. R.: Water activities, densities, and refractive indices of aqueous sulfates and sodium nitrate droplets of atmos pheric importance, J. Geophys. Res., 99(D9), 18801-18808, 1994.

Tang, I. N., Chemical and size effects of hygroscopic aerosols on light scattering coefficients, J. Geophys. Res., 101 (D14), 19245-19250, 1996.

Ting, L., Andreas, Z., Yafang, C., Hang, S., Weigang, W., Mao-Fa, G.: Hy groscopicity of org anic surrogate compounds from biomas s burning and their effect on the efflorescence of ammoniumsulfate in mixed aerosol particles., Atmos. Chem. Phys.

1005 Discuss., 1-42. 10.5194/acp-2017-549, 2017.

Tombette, M., Chazette, P., Sportis se, B., and Roustan, Y.: Simulation of aerosol optical properties over Europe with a 3-D size-resolved aerosol model: comparisons with AERONET data, Atmos. Chem. Phys., 8, 7115-7132, https://doi.org/10.5194/acp-8-7115-2008, 2008.

Toon, O. B., and Pollack, J. B.: A Global Average Model of Atmospheric Aerosols for Radiative Transfer Calculations, J. Appl. Meteor., 15, 225-246, https://doi.org/10.1175/1520-0450(1976)015<0225:AGAMOA>2.0.CO;2, 1976.

Toon, O. B., Pollack, J. B., Khare, B. N.: The optical constants of several atmospheric aerosol species: Ammonium sulfate, aluminum oxide, and sodiumchloride, J. Geophys. Res., 81(33), 5733-5748, 1976.

U.S. Environmental Protection Agency (EPA) 2011 Air Emis sions Modelling Version 6.3 Platform, https ://www.epa.gov/airemissions-modeling/2011-version-63-platform, last access 1 December 2020.

1015 U.S. Environmental Protection Agency (EPA) 2011 Air Emis sion Modelling Version 6.2 Platform, https ://www.epa.gov/airemissions-modeling/2011-version-62-platform, last access 1 December 2020.

Van Wagner, C.E.: Development and structure of the Canadian Forest Fire Weather Index System. Can. For. Serv., Ottawa, Ont. For. Tech. Rep. 35.37 pp., 1987.

Yamamoto, G. and Tanaka, M.: Increase of global albedo dueto air pollution, J. Atmos. Sci., 29, 1405-1412, 1972.

1020 Zamora,I. R. and Jacobson, M.Z.: Measuring and modeling thehygroscopic growth of two humic substances in mixed aerosol particles of atmos pheric relevance, Atmos. Chem. Phys., 13, 8973-8989, https://doi.org/10.5194/acp-13-8973-2013, 2013.

Zhang, L., Gong, S., Padro, J., and Barrie, L.: A size-segregated particle dry deposition scheme for an atmospheric aerosol module, Atmos. Environ., 35, 549-560, 2001. 